\title{
A systematic review and realist synthesis on toilet paper hoarding: COVID or not COVID, that is the question
}

\author{
Javier Labad $^{\text {Corresp., 1, 2, } 3}$, Alexandre González-Rodríguez ${ }^{3,4,5}$, Jesus Cobo ${ }^{2,3,4,5}$, Joaquim Puntí ${ }^{5}$, Josep Maria Farré ${ }^{6}$ \\ 1 Department of Mental Health, Consorci Sanitari del Maresme, Mataró, Spain \\ 2 Centro de Investigación Biomédica en Salud Mental (CIBERSAM), Madrid, Spain \\ 3 Institut d'Investigació Sanitària Parc Taulí (I3PT), Sabadell, Spain \\ 4 Department of Psychiatry and Legal Medicine, Universitat Autónoma de Barcelona, Cerdanyola del Vallès, Spain \\ 5 Department of Mental Health, Parc Taulí Hospital Universitari, Sabadell, Spain \\ 6 Department of Psychiatry, Psychology and Psychosomatics, Dexeus University Hospital, Barcelona, Spain \\ Corresponding Author: Javier Labad \\ Email address: jlabad@csdm.cat
}

Objective: To explore whether the coronavirus disease 2019 (COVID-19) pandemic is associated with toilet paper hoarding and to assess which risk factors are associated with the risk of toilet paper hoarding.

Design: A systematic review and realist review were conducted.

Data sources: PubMed, Web of Science, Scopus and PsycINFO were searched (systematic review). PubMed, pre-prints and grey literature were also searched (realist review). The databases were searched from inception until June 2020.

Study selection: There were no restrictions on the study design.

Outcomes and measures: For the systematic review, toilet paper hoarding was the main outcome, and pathological use of toilet paper was the secondary outcome. For the realist review, the contextmechanisms-outcome (CMO) scheme included the COVID-19 pandemic (context), four proposed mechanisms, and one outcome (toilet paper hoarding). The four potential mechanisms were 1) gastrointestinal mechanisms of COVID-19 (e.g., diarrhoea), 2) social cognitive biases, 3) stress-related factors (mental illnesses, personality traits), and 4) cultural aspects (e.g., differences between countries).

Eligibility criteria for selecting studies: All studies of human populations were considered (including general population studies and clinical studies of patients suffering from mental health problems).

Results: The systematic review identified 14 studies (8 studies for the main outcome, 6 studies for the secondary outcome). Three surveys identified the role of the COVID-19 threat in toilet paper hoarding in the general population. One study pointed to an association between a personality trait (conscientiousness) and toilet paper buying and stockpiling as well as an additional significant indirect effect of emotionality through the perceived threat of COVID-19 on toilet paper buying and stockpiling. Six case reports of pathological use of toilet paper were also identified, although none of them were associated with the COVID-19 pandemic. The realist review suggested that of all the mechanisms, social cognitive biases and a bandwagon effect were potential contributors to toilet paper hoarding in the general population. The stressful situation (COVID-19 pandemic) and some personality traits

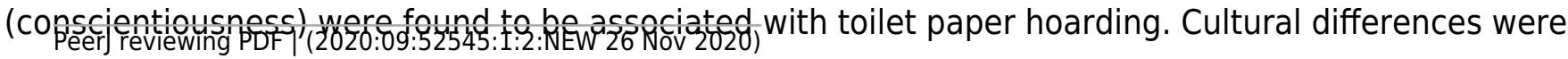


also identified, with relatively substantial effects of toilet paper hoarding in several Asian regions (Australia, Japan, Taiwan and Singapore).

Conclusions: The COVID-19 pandemic has been associated with a worldwide increase in toilet paper hoarding. Social media and social cognitive biases are major contributors and might explain some differences in toilet paper hoarding between countries. Other mental health-related factors, such as the stressful situation of the COVID-19 pandemic, fear of contagion, or particular personality traits (conscientiousness), are likely to be involved.

Registration: PROSPERO CRD42020182308 


\section{A systematic review and realist synthesis on toilet}

2 paper hoarding: COVID or not COVID, that is the

\section{3 question}

4

5

6

7

8

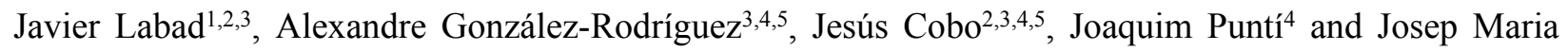
Farré $^{6}$ on behalf of the Catalan Toilet Tissue Research Group in Mental Health (CATOTIM).

${ }^{1}$ Department of Mental Health, Consorci Sanitari del Maresme. Mataró, Spain.

${ }^{2}$ Centro de Investigación Biomédica en Salud Mental (CIBERSAM). Spain.

${ }^{3}$ Institut d'Investigació i Innovació Parc Taulí (I3PT). Sabadell, Spain

${ }^{4}$ Department of Mental Health, Parc Taulí Hospital Universitari, I3PT. Sabadell, Spain.

${ }^{5}$ Department of Psychiatry and Legal Medicine, Universitat Autònoma de Barcelona. Cerdanyola del Vallès, Spain.

${ }^{6}$ Department of Psychiatry, Psychology and Psychosomatics, Dexeus University Hospital. Barcelona, Spain

Corresponding Author:

Javier Labad

Department of Mental Health, Consorci Sanitari del Maresme

Carr. de Cirera, 230, 08304 Mataró, Spain

Email: jlabad@csdm.cat

\section{Abstract}

Objective: To explore whether the coronavirus disease 2019 (COVID-19) pandemic is associated with toilet paper hoarding and to assess which risk factors are associated with the risk of toilet paper hoarding. Design: A systematic review and realist review were conducted.

Data sources: PubMed, Web of Science, Scopus and PsycINFO were searched (systematic review). PubMed, pre-prints and grey literature were also searched (realist review). The databases were searched from inception until June 2020.

Study selection: There were no restrictions on the study design.

Outcomes and measures: For the systematic review, toilet paper hoarding was the main outcome, and pathological use of toilet paper was the secondary outcome. For the realist review, the contextmechanisms-outcome (CMO) scheme included the COVID-19 pandemic (context), four proposed 
mechanisms, and one outcome (toilet paper hoarding). The four potential mechanisms were 1) gastrointestinal mechanisms of COVID-19 (e.g., diarrhoea), 2) social cognitive biases, 3) stress-related factors (mental illnesses, personality traits), and 4) cultural aspects (e.g., differences between countries).

Eligibility criteria for selecting studies: All studies of human populations were considered (including general population studies and clinical studies of patients suffering from mental health problems).

Results: The systematic review identified 14 studies $(8$ studies for the main outcome, 6 studies for the secondary outcome). Three surveys identified the role of the COVID-19 threat in toilet paper hoarding in the general population. One study pointed to an association between a personality trait (conscientiousness) and toilet paper buying and stockpiling as well as an additional significant indirect effect of emotionality through the perceived threat of COVID-19 on toilet paper buying and stockpiling. Six case reports of pathological use of toilet paper were also identified, although none of them were associated with the COVID-19 pandemic. The realist review suggested that of all the mechanisms, social cognitive biases and a bandwagon effect were potential contributors to toilet paper hoarding in the general population. The stressful situation (COVID-19 pandemic) and some personality traits (conscientiousness) were found to be associated with toilet paper hoarding. Cultural differences were also identified, with relatively substantial effects of toilet paper hoarding in several Asian regions (Australia, Japan, Taiwan and Singapore).

Conclusions: The COVID-19 pandemic has been associated with a worldwide increase in toilet paper hoarding. Social media and social cognitive biases are major contributors and might explain some differences in toilet paper hoarding between countries. Other mental health-related factors, such as the stressful situation of the COVID-19 pandemic, fear of contagion, or particular personality traits (conscientiousness), are likely to be involved.

Registration: PROSPERO CRD42020182308 


\section{Introduction}

60 Toilet paper, sometimes called toilet tissue or loo roll, is defined by the Merriam-Webster dictionary as "a 61 thin sanitary absorbent paper usually in a roll for use in drying or cleaning oneself after defecation and urination". To wipe is human, and paper has been used for faecal-related cleaning purposes since the end of the 6th century in China, although the toilet paper industry blossomed in the early 14th century in China during the reign of the Yang dynasty (Smyth, 2012). The commercial use of toilet paper started in 1857 thanks to Joseph Gayetty, a New York-based entrepreneur who sold medicated paper infused with aloe that aimed to cure haemorrhoids (Smyth, 2012). The reception of toilet paper from the medical community was not positive, and in an ironic note published in the Lancet in 1869, the idea of toilet paper was defined as "the last absurdity" (The Lancet, 1869). The note was sarcastic when referring to the opinion of Gayetty, who anticipated that "this article will be found in the household of every refined man in the kingdom". Many years later, toilet paper has become an essential product for a great proportion of the population worldwide.

Since early December 2019, the coronavirus SARS-CoV-2 has spread from Wuhan (China) to many countries worldwide, causing the coronavirus disease 2019 (COVID-19). In terms of deaths, COVID-19 has been the worst pandemic since the 1918 flu pandemic, also known as the Spanish flu (although its origin was in Kansas, USA (Worobey, Cox \& Gill, 2019)). By November 11th, 2020, the COVID-19 pandemic had caused at least 51,251,715 infections and 1,270,930 deaths (WHO Coronavirus Disease (COVID-19) Dashboard). During the first months of the pandemic, medical masks were in short supply in most countries. This issue was expected because SARS-CoV-2 is viable and infectious in aerosols for hours (van Doremalen et al., 2020), and using face masks is advised in situations where meeting others is likely, as masks can reduce the risk of transmitting the infection (Greenhalgh et al., 2020). The global toilet paper shortage amid the coronavirus was much less expected, but in the weeks that followed the pandemic spread, compulsive panic buying of toilet paper was observed in many countries on different continents (Buchholz, 2020). Toilet paper became a co-star with coronavirus in the news in many countries, with surprising information every week: rationing of toilet paper by supermarkets (Pidd, 2020), toilet rolls being chained to their dispensers in public toilets (Lewis, 2020), armed robbers stealing hundreds of paper rolls (Leung, 2020), and deserted supermarket and grocery shelves (Knoll, 2020). People were buying and hoarding toilet paper even before it was known that the virus could be detected in the faeces of infected patients (Chen et al., 2020a) or that approximately 10\% of COVID-19 patients may suffer from diarrhoea (Miri et al., 2020). Therefore, a scientific question demands an urgent response: why do people hoard toilet paper?

We aimed to shed light on potential risk factors associated with toilet paper hoarding, with a particular interest in stress-related situations such as the COVID-19 pandemic. As hoarding is often seen in patients with obsessive-compulsive disorder (OCD) and other psychiatric disorders as well as in people with obsessive-compulsive traits (Mataix-Cols et al., 2010), it is important to make the differential diagnosis with mental health problems. In most individuals, compulsive hoarding appears to be a syndrome distinct from OCD, which is associated with substantial levels of disability and social isolation (Pertusa et al., 2008). This has led to the inclusion of hoarding as a separate diagnosis in the 5th edition of the Diagnostic and Statistical Manual of Mental Disorders (DSM-5). One hoarding criterion is the acquisition of and failure to discard a large number of possessions that seem to be useless or of limited value (Mataix-Cols et al., 2010). We are not currently interested in addressing the debate about the utility of toilet paper, but it is important to mention that to date, toilet paper is not a specifier of the DSM-5 diagnostic criteria for hoarding. Moreover, there is no previous evidence suggesting that toilet paper hoarding is a behaviour 
103

104

105

106

107

108

109

110

111

112

113

114

115

116

117

118

119

120

121

122

123

124

125

126

127

128

129

130

131

132

133

134

135

136

137

138

139

140

141

142

143

144

145

146

distinct from other hoarding behaviour. Epidemiological studies suggest that hoarders are older, often unmarried, and more likely to be impaired by a current physical health condition or comorbid mental disorder (Nordsletten et al., 2013). There is limited information regarding the prevalence of toilet paper hoarding in the general population.

It is also important to underscore that compulsive buying and hoarding are two related phenomena, as hoarding is a predictor of compulsive buying (Lawrence, Ciorciari \& Kyrios, 2014). Moreover, people with buying-shopping disorder report more hoarding symptoms than healthy control individuals (Vogel et al., 2019). Both buying and hoarding behaviour have been described as being preceded by stressful life events and traumatic experiences (Tolin et al., 2010; Landau et al., 2011; Vogel et al., 2019). For this reason, it is important to study how stress influences hoarding behaviour because this knowledge would help to understand some of the recent panic-buying behaviour seen in the weeks following the COVID-19 pandemic.

As hoarding behaviours are observed in both non-clinical (Bulli et al., 2014) and clinical (Pertusa et al., 2008) samples, studies considering non-clinical populations need to be considered. It is also important to analyse whether the mechanisms linking stress with toilet paper hoarding are shared by people with mental disorders (hoarding disorders and other psychiatric disorders) and the general population or whether this relationship might change depending upon the social or cultural context.

Neuroimaging studies using functional magnetic resonance imaging (fMRI) and conducting experimental approaches (provocation of hoarding-related anxiety) in healthy subjects and clinical populations (OCD patients) have demonstrated that hoarding symptoms are associated with activation of the same brain areas, involving the anterior ventromedial prefrontal cortex, in both non-clinical and clinical populations (Mataix-Cols et al., 2003; An et al., 2009). These results support a common transdiagnostic neurobiological pathway for hoarding symptoms. Interestingly, the anterior ventromedial prefrontal cortex has also been implicated in buying behaviour in studies exploring value-based decisions with a buying task during an fMRI session (Gluth et al., 2012).

The main objective of our study was to identify potential mechanisms linking the context of a stressful situation (COVID-19 pandemic) with a specific outcome (toilet paper hoarding). We also aimed to study potential mechanisms involved in hoarding behaviour that might be influenced by psychopathological, psychological, social and cultural determinants that could act as moderators.

To achieve these objectives, we conducted one study that included two sequential steps:

First, we conducted a systematic review exploring potential risk factors associated with toilet paper hoarding. Psychopathology, personality and stress-related factors (including pandemics, especially the COVID-19 pandemic) were considered. The main hypothesis of our systematic review was that a substantial proportion of the general population would hoard toilet paper amid the COVID-19 pandemic. As a secondary aim of the systematic review, we also wanted to study whether toilet paper use (pathological use and/or hoarding) is associated with negative mental health outcomes (e.g., greater risk of depression, suicide). This secondary aim was exploratory in nature.

Second, we conducted a realist review exploring different theory-driven mechanisms on potential moderators of the relationship between the COVID-19 pandemic and toilet paper hoarding (Table 1). A realist review is based on a realist philosophy of science and considers the interaction among context, mechanism and outcome, also known as the CMO configuration (Wong et al., 2013). As explained in the RAMESES guidelines for realist syntheses (Wong et al., 2013), this type of review uses the concept of a mechanism for understanding the relationship between context and outcome. Several mechanisms might

Peer] reviewing PDF | (2020:09:52545:1:2:NEW 26 Nov 2020) 
147 be studied and can be defined as "underlying entities, processes, or (social) structures which operate in

148 particular contexts to generate outcomes of interest". A realist review is an interpretative type of literature

149 review, in contrast with a systematic review that attempts to collect all empirical evidence that fits pre-

150 specified eligibility criteria in order to answer a specific research question (Berg \& Nanavati, 2016).

151 Regarding the realist review, four hypotheses were formulated in relation to different mechanisms that

152 might partially explain toilet paper hoarding during the COVID-19 pandemic: 1) diarrhoea or polyuria

153 contributes to panic buying and toilet paper hoarding; 2) social cognitive biases and social media facilitate

154 the hoarding of toilet paper; 3) stress contributes to the worsening of mental health outcomes that could

155 also increase the risk of toilet paper hoarding; and 4) cultural aspects moderate the relationship between

156 the COVID-19 pandemic and toilet paper hoarding.

157 Finally, several recommendations for future research will be included considering the gaps in the

158 scientific literature. Clinical and ecological implications of our research will also be summarised.

\section{Materials \& Methods}

\section{Systematic review}

161 Preferred Reporting Items for Systematic Reviews and Meta-analyses (PRISMA) guidelines

162 (Moher et al., 2009) were followed. The protocol was registered in PROSPERO

163 (CRD42020182308).

164 Search strategy

165 Four electronic bibliographic databases were searched: PubMed, Web of Science, Scopus and

166 PsycINFO. The following search strategy was used: (Toilet AND (paper OR tissue OR roll))

167 AND (psychiatry OR psychology OR mental OR anxiety OR depression OR schizophrenia OR

168 bipolar OR psychosis OR delusion OR personality OR neuroticism OR obsessive OR hoarding

169 OR suicide OR stress* OR pandemic OR epidemic OR COVID-19 OR coronavirus OR virus).

170 The search strategy was performed by J.L. and A.G.R. Studies published through $31^{\text {st }}$ October

1712020 were considered for inclusion.

172 Inclusion and exclusion criteria

173 In our systematic review, toilet paper hoarding was considered the main outcome. This outcome

174 was defined as a behavioural pattern characterised by excessive acquisition of and an inability or

175 unwillingness to discard large quantities of toilet paper that cause significant distress or

176 impairment. This definition is in agreement with the current DSM-5 diagnostic category for

177 hoarding disorder, but it has been adapted for specifying that the main item saved is toilet paper.

178 We also conducted a secondary analysis for the systematic review that considers toilet paper

179 (pathological use or hoarding) as a risk factor for mental health outcomes (depression, suicide,

180 etc.).

181 In those studies using toilet paper as an outcome (e.g., toilet paper hoarding), all potential

182 exposures (stress-related situations, personality factors, psychopathology, and mental illnesses)

183 were considered. In those studies with toilet paper use as an exposure, the considered outcomes

184 were mental health problems (e.g., depression, suicide).

185 All types of studies that relate to mental health or stress-related aspects of toilet paper use were

186 included. There were no restrictions on the types of study design. All studies conducted in

187 human populations (general population studies and clinical studies of patients suffering from 
188

189

190

191

192

193

194

195

196

197

198

199

200

201

202

203

204

205

206

207

208

209

210

211

212

213

214

215

216

217

218

219

220

221

222

223

224

225

226

mental health problems) were considered for inclusion. Language was restricted to articles written English, Spanish, Catalan, Portuguese, Dutch, French, or German. There was no restriction on the type of document indexed in the electronic databases (these documents could include original articles, reviews, letters to the editor, case reports, editorials, conference proceedings). We included published documents in the systematic review, and therefore, preprints were not included in the systematic review (they could be included in the realist review).

Data collection and extraction

All retrieved records were checked for duplicates using Covidence (https://www.covidence.org/).

The titles and/or abstracts of studies retrieved using the search strategy and those from additional sources were screened independently by two review authors (J.L. and A.G.R.) to identify studies that met the inclusion criteria. Any disagreement between them over the eligibility of particular studies was resolved through discussion with two additional reviewers (J.C. and J.P). The flow chart of all selected studies is described in Figure 1.

\section{$\underline{\text { Risk of bias (quality) assessment }}$}

Quality assessment was conducted with the Newcastle Ottawa Scale (cohort and case-control studies) (Wells et al., 2012) or the CARE guidelines (case reports) (Riley et al., 2017). Case reports and case series are also rated with the tool for evaluating the methodological quality of case reports and case series (Murad et al., 2018).

\section{Realist review}

A realist synthesis was conducted following the RAMESES guidelines (Wong et al., 2013). An additional reviewer (J.C.) participated in the search for potential citations along with the two researchers participating in the systematic review (J.L. and A.G.R.). We started by considering all reviewed items in the previous step with the theory-driven approach of the realist review. Four mechanisms were tested (Table 1). Iterative screening was completed by these reviewers, who also conducted additional searches to explore these hypotheses on PubMed as well as grey literature available on the internet (e.g., Google searching). Search terms differed for each mechanism: 1) Mechanism 1: covid AND (diarrhoea OR polyuria); 2) Mechanism 2: (stress OR covid OR pandemic) AND cognitive bias AND social; 3) Mechanism 3: (covid OR stress OR pandemic) AND hoarding; and 4) Mechanism 4: (toilet paper OR hoarding) AND (culture OR cultural). All potential abstracts were included if they could contribute to explaining any of the four studied mechanisms linking the COVID-19 pandemic with toilet paper hoarding. The identification and selection of citations were guided by these research questions and were based on the trustworthiness of sources. This last characteristic is not easy to verify, as fake news is mixed with real news all over the internet. We tried to reduce the inclusion of fake news by carefully observing the sources, particularly when they came from non-peer-reviewed sources. 
227 To explore differences in cultural aspects of toilet paper hoarding, we also verified the Google

228

229

230

231

232

233

234

235

236

237

238

239

240

241

242

243

244

245

246

247

248

249

250

251

252

253

254

255

256

257

258

259

260

261

262

263

264

265

266

search trending topics during the year of 2020 in the world (https://trends.google.com/). Previous research indicates that Google search data are useful in predicting near-future consumer behaviour (Goel et al., 2010). The search frequency on Google has also been proposed as a direct measure of investor attention (Da, Engelberg \& Gao, 2011). Data regarding the use of toilet paper were graphed with Excel (Microsoft Corporation, USA) after downloading the .csv file. We also compared two search terms (toilet paper vs covid) to analyse the relative popularity of the term "toilet paper" with respect to the "COVID" term.

Qualitative studies and material were managed with the software QDA miner Lite version 2.0.7 (Provalis Research, Canada). Data regarding the potential contribution of the studied mechanisms were extracted. To identify key elements of importance to the success or failure of a mechanism in a certain context using a realist perspective, information was gathered on the mechanism, the context and the actual "working of the mechanism". The strength of the evidence and the usefulness of the application of realist principles to available data were discussed.

\section{Results}

\section{Systematic review}

A total of 1337 records were identified in initial searches (Web of Science: 489; Scopus: 245, PubMed: 532; PsycINFO: 71). After duplications were removed, 576 records were screened after reading the title and abstract. Further details of the screening and selection processes can be found in Figure 1. Finally, 13 studies were included because they were focused on toilet paper hoarding behaviour and met our selection criteria.

Primary outcome: toilet paper hoarding

We identified 8 published studies related to the COVID-19 pandemic with toilet paper hoarding (Garbe, Rau \& Toppe, 2020; Kirk \& Rifkin, 2020; Oosterhoff \& Palmer, 2020; Sim et al., 2020; Miri et al., 2020; Micalizzi et al., 2020; Laato et al., 2020; Güzel, 2020). One study included a survey of participants focused on toilet paper shopping and stockpiling behaviours (Garbe, Rau \& Toppe, 2020), one study conducted a survey of adolescents regarding several pandemicrelated behaviours (including hoarding) (Oosterhoff \& Palmer, 2020), and another study conducted a survey through Amazon's Mechanical Turk on stockpiling behaviour (including toilet paper) in response to COVID-19 (Micalizzi et al., 2020). One study analysed purchasing behaviour during the COVID-19 pandemic (Laato et al., 2020). The other four published studies included theoretical discussions on consumption behaviours, including panic buying during the COVID-19 pandemic (Kirk \& Rifkin, 2020; Sim et al., 2020; Miri et al., 2020; Güzel, 2020). The first study (Garbe, Rau \& Toppe, 2020) explored the relationship between personality traits based on the HEXACO model (Honesty-Humility, Emotionality, eXtraversion, Agreeableness, Conscientiousness, and Openness to experience). This study was a survey that included a final sample of 996 adults from 22 countries. Participants were asked about their perception of the level of threat posed by COVID-19 and their toilet paper consumption behaviour (shopping 
267 frequency, shopping intensity, number of toilet paper rolls stocked in their household). Older 268 participants shopped more frequently, bought more packages of toilet paper and had more toilet

269

270

271

272

273

274

275

276

277

278

279

280

281

282

283

284

285

286

287

288

289

290

291

292

293

294

295

296

297

298

299

300

301

302

303

304

305 paper rolls in stock than younger participants. Participants residing in Europe shopped for toilet paper significantly more frequently than North American residents but had less toilet paper in stock. In this study, participants were asked about whether they stocked toilet paper more than usual, which could be considered an indirect measure of toilet paper hoarding. Of all participants in the survey, $17.2 \%$ of North Americans and 13.7\% of Europeans reported stockpiling toilet paper. The perceived threat of COVID-19 was positively related to all three toilet paper variables (shopping frequency, shopping intensity and toilet paper stockpiling). The HEXACO model suggested that participants scoring high in conscientiousness (organisation, diligence, perfectionism, and prudence) shopped for toilet paper more and stocked more toilet paper. This study also included an additional analysis exploring the indirect effect of emotionality (fearfulness, anxiety, dependence, and sentimentality) on toilet paper consumption. They found a significant indirect effect of emotionality through the perceived threat of COVID-19 on shopping intensity and the amount of stocked toilet paper rolls. In the quality assessment with the Newcastle Ottawa Scale for this study, we considered the perceived threat of COVID-19 as the main exposure and toilet paper behaviour as the main outcome (definition of cases). The quality assessment yielded two stars for selection (representativeness of cases, selection of controls), two stars for comparability and one star for the definition of the exposure. Therefore, this study obtained 5 of 9 possible stars on the Newcastle Ottawa Scale.

Another survey of 770 adolescents in the United States explored the role of psychological factors in pandemic-related behaviours during the COVID-19 outbreak (social distancing, disinfecting, monitoring the news, hoarding supplies) (Oosterhoff \& Palmer, 2020). In this study, attitudes about the greater severity of COVID-19 and greater self-interest values were associated with more hoarding, whereas greater social responsibility and social trust were associated with less hoarding. In the quality assessment with the Newcastle Ottawa Scale for this study, we considered attitudes about the severity of COVID-19 as the main exposure and hoarding behaviour as the main outcome (definition of cases). This study obtained 5 out of 9 stars on the Newcastle Ottawa Scale (selection [two stars], comparability [two stars], definition of exposure [one star]).

One survey of 363 workers in the United States who were recruited from Amazon's Mechanical Turk inquired about the stockpiling of 13 items, as well as opinions on the COVID-19 pandemic and political affiliation (Democrat vs Republican) (Micalizzi et al., 2020). Of all 13 items, toilet paper was the item most commonly stockpiled (63.2\%). However, more than half of the sample reported stockpiling other supplies, such as canned goods $(59.2 \%)$, rice $(57.4 \%)$, bottled water $(57.0 \%)$, pasta $(56.2 \%)$, bread (53\%) and medicine $(52.7 \%)$. When looking at predictors of increased stockpiling with multivariate analyses that were adjusted for education status, income, age and number of people living at home, higher stockpiling was observed among those who were more conservative, worried more about the pandemic, had more people in the home, and 
306 reported less social distancing. This study obtained 4 out of 9 stars on the Newcastle Ottawa

307 Scale (selection [one star], comparability [two stars], definition of exposure [one star]).

308

309

310

311

312

313

314

315

316

317

318

319

320

321

322

323

324

325

326

327

328

329

330

331

332

333

334

335

336

337

338

339

340

341

342

343

344

345

Five studies reflected on potential explanations for toilet paper hoarding amid the COVID-19 pandemic and justified this behaviour with different hypotheses, such as a reaction to a threat to product availability that increases the perceived need for the threatened object and makes consumers behave with an emotionally reactive response (Kirk \& Rifkin, 2020). Other potential moderators included the conflict between the desire to maintain regular routines versus the uncertainty of limiting access to daily necessities by the pandemic, a coping response to stressful unmet situations or even a reaction to the loss of control of the future and social pressures to conform to similar behaviours (Sim et al., 2020). Another study testing potential contributors of toilet paper hoarding during the COVID-19 pandemic in a Finnish sample (Laato et al., 2020) proposed a structured model connecting exposure to online information sources to two behavioural responses (unusual purchases and voluntary self-isolation). Exposure to online information increased health anxiety as measured by cyberchondria and consequently the intention to make unusual purchases and engage in voluntary isolation.

In another systematic review on gastrointestinal symptoms of COVID-19 that indicates the long persistence of COVID-19 in the gastrointestinal tract after primary treatment (Miri et al., 2020), the authors suggested that these findings could explain the coronavirus-related panic buying of toilet rolls.

Finally, another study was a personal reflection about the panic buying and hoarding of toilet paper during the COVID-19 pandemic from a psychodynamic perspective (Güzel, 2020).

Secondary outcome: toilet paper (pathological use or hoarding) and mental health outcomes Six case reports of pathological use of toilet paper hoarding were identified. One study reported a case of a patient with therapy-resistant OCD who spent hours on the toilet with excessive anus wiping, using at least 10 rolls of toilet paper per day (Klimke et al., 2016). Interestingly, with only two applications of transcranial alternating current stimulation (tACS), the patient showed immediate improvement (using less than one toilet roll per day).

Two case reports indicated suicide by mechanical asphyxia using toilet paper: one patient suffering from schizophrenia (Sauvageau \& Yesovitch, 2006) and another patient with borderline personality disorder (Saint-Martin, Bouyssy \& O’Byrne, 2007). It is not always easy to distinguish suicide from homicide, and another study reported the case of a homicide by toilet paper smothering in a patient with Alzheimer's disease (Saint-Martin, Lefrancq \& Sauvageau, 2012).

Two other case reports described patients with pica, a syndrome characterised by unusual craving for the ingestion of either edible or inedible substances, who ate toilet paper (Chisholm \& Martin, 1981; Fisher et al., 2014). The diagnosis of this syndrome is a clinical challenge because this condition might be underreported and is sometimes diagnosed after studying medical complications such as iron deficiency and gastrointestinal bleeding (Fisher et al., 2014).

Peer) reviewing PDF | (2020:09:52545:1:2:NEW 26 Nov 2020) 
346 In other cases, biochemical deficiencies need to be studied because hypozincaemia might play a 347 role in the ingestion of toilet paper (Chisholm \& Martin, 1981).

348 All six case reports are described in Table 2. The quality of the studies assessed with the CARE 349 guidelines (Table 2) and the recommendations by Murad et al. (Murad et al., 2018) (Table S1)

350 351

352

353

354

355 356

357

358

359

360

361

362

363

364

365

366

367

368

369

370

371

372

373

374

375

376

377

378

379

380

381

382

383

384

385 was good. None of these case reports was related to the COVID-19 pandemic.

\section{Realist review}

The PubMed search for the four theory-driven mechanisms (M1 to M4, Table 1) included a total of 452 records (M1: 108; M2: 104; M3: 80; M4: 60). After the review by three authors, 92 records were selected. Fourteen additional records from grey literature were also included.

COVID-19 disease is associated with diarrhoea (or polyuria), which contributes to panic buying and toilet paper hoarding (Mechanism \#1)

Most clinical studies suggest that up to $10 \%$ of patients suffering from COVID-19 suffer from diarrhoea (Chen et al., 2020c; Guan et al., 2020; Huang et al., 2020; Jin et al., 2020; Kim et al., 2020; Li et al., 2020b; Liu et al., 2020; Xu et al., 2020b; Zhang et al., 2020b), although some studies reported higher rates, between 15\% and 34\% (Chen et al., 2020b; Pan et al., 2020; Wang et al., 2020a; Zhao et al., 2020). One study (Lei et al., 2020) comparing the clinical features of patients with COVID-19 in Wuhan and outside Wuhan (Guangzhou, China) reported a greater proportion of diarrhoea in the subsample of patients outside Wuhan (25\% vs $2 \%)$. Another study suggests that the prevalence of diarrhoea is greater (18.8\%) in hospitalised frontline medical workers from Wuhan (Wang et al., 2020b). A recent meta-analysis that included 58 studies with COVID-19 patients with data on the prevalence of diarrhoea reported a pooled prevalence of diarrhoea of 12.5\% (95\% CI, 9.6-16.0) (Cheung et al., 2020). A similar prevalence (12.9\%) was also reported by another meta-analysis including 24 studies (Zhu et al., 2020). Other studies in European countries have found even higher rates of diarrhoea, up to half of patients (Klopfenstein et al., 2020; Lechien et al., 2020).

A study exploring the clinical characteristics of COVID-19 patients without or with gastrointestinal symptoms (nausea, vomiting or diarrhoea) suggests that the gastrointestinal expression of symptoms is associated with some risk factors (family clustering in exposure, preexisting chronic liver disease) and with a more severe/critical type of the disease and higher rates of body temperature $>38.5^{\circ} \mathrm{C}$ (Jin et al., 2020). However, the association between diarrhoea and greater disease severity has not been a well-replicated finding, and meta-analysis suggests that there is no relationship between this gastrointestinal symptom and the severity of the COVID-19 disease (Henry et al., 2020). Another study pointed out that 19.4\% of COVID-19 patients with gastrointestinal symptoms experienced diarrhoea as their first symptom before the onset of respiratory symptoms (Han et al., 2020).

The SARS-CoV-2 protein interacts with human angiotensin-converting enzyme 2 (ACE2) molecules, which are highly expressed in absorptive enterocytes from the ileum and colon (Adhikari et al., 2020; Zhang et al., 2020a). ACE2 is recognised as an important regulator of 
386

387

388

389

390

391

392

393

394

395

396

397

398

399

400

401

402

403

404

405

406

407

408

409

410

411

412

413

414

415

416

417

418

419

420

421

422

423

424

425

intestinal inflammation, and it has been hypothesised that this is the causal mechanism of diarrhoea in COVID-19 (Ong, Young \& Ong, 2020). The SARS-CoV-2 binding affinity for human ACE2 is significantly stronger (10-20 times greater) than its 2003 SARS-CoV predecessor (D'Amico et al., 2020). Already in February, some authors suggested that faecal-oral transmission of SARS-CoV-2 was possible (Yeo, Kaushal \& Yeo, 2020), with later studies confirming the presence of SARS-CoV-2 RNA in stool specimens of approximately 53-66\% of patients (Chen et al., 2020a; Xiao et al., 2020), independent of the presence of gastrointestinal symptoms or the severity of illness (Chen et al., 2020a). There have been cases in which the SARS-CoV-2 test was negative in the nasopharyngeal swab test after treatment but the rectal test swab specimens still tested positive (Wei et al., 2020), particularly in paediatric patients (Xu et al., 2020a), suggesting that the rectal swab may be equally as important as the pharyngeal swab (He et al., 2020). Surveillance and adequate disinfection in latrines in areas with severe SARSCoV-2 infection to avoid fomite transmission have also been recommended by some authors (He et al., 2020), as well as avoiding sharing toilets with families for patients with COVID-19 when discharged to home (Li et al., 2020a). As upper gastrointestinal endoscopy can induce coughing and lower gastrointestinal endoscopy can generate aerosol droplets as air is expelled from patients, preparedness for personal protective equipment in the endoscopy setting has also been recommended (Ong, Young \& Ong, 2020; Wong, Lui \& Sung, 2020).

Previous research has not detected viral RNA in urine specimens (Wang et al., 2020c). We did not find studies reporting a direct effect of SARS-CoV-2 on polyuria. However, it is important to underscore that in patients with diabetes, COVID-19 might induce diabetic ketoacidosis ( $\mathrm{Li}$ et al., 2020c), which is a cause of polyuria.

Finally, no studies about toilet paper usage or hoarding in patients with COVID-19 were found.

Social cognitive biases and social media as facilitators of toilet paper hoarding (Mechanism \#2) Social cognitive biases might contribute to the mimicking of conduct by other people. A particularly pivotal role in socially replicated conduct is the bandwagon effect, which might be defined as a phenomenon where the rate of uptake of beliefs, ideas, fads and trends increases the more that they have already been adopted by others (O'Connor \& Clark, 2019). This effect has been applied in politics since the 19th century, with the term "jump on the bandwagon" coined when the circus clown Dan Rice used a bandwagon for the political campaign of future-president Zachary Taylor (Chappelow, 2019). This effect might be used to explain some behaviours, such as buying paper toilet rolls if everyone else is buying them. In fact, toilet paper hoarding is a phenomenon that has been proven to be sensitive to this bandwagon effect in other time periods. For instance, in December 1973, in a time of shortages in the United States due to the OPEC oil embargo, Johnny Carson made a joke during his opening monologue of The Tonight Show about an upcoming toilet paper shortage and triggered a nationwide toilet paper buying spree (Malcom, 1974). Moreover, stress-related situations might also be involved (e.g., the oil crisis in 1973 and the COVID-19 pandemic in 2019-2020), as stress is thought to potentiate decision biases along with a shift from deliberative to intuitive thinking ( $\mathrm{Yu}, 2016$; Jacob et al., 2017). Information 
426 bias during decision making favours considering the benefits of saving and the costs of 427 discarding, which can lead to hoarding behaviour (Steketee \& Frost, 2003). As already 428 mentioned, the study by Laato et al. (2020) suggests that exposure to online information might 429 contribute to increased buying behaviour and hoarding during the COVID-19 pandemic. The 430 findings of this study also suggest that the intention to self-isolate was a major reason why 431 people made unusual purchases during COVID-19 (to prepare for isolation and quarantine). 432 People with acute stress disorder report more cognitive biases pertaining to external harm, 433 somatic sensations and social events (Smith \& Bryant, 2000), suggesting that stress moderates

434

435

436

437

438

439

440

441

442

443

444

445

446

447

448

449

450

451

452

453

454

455

456

457

458

459

460

461

462

463

464 reasoning capability. Socially anxious people are more prone to interpret emotionally ambiguous situations as threatening or negative, also known as interpretation bias, which is involved in the maintenance of anxiety and stress reactivity (Badra et al., 2017; Van Bockstaele et al., 2019).

Some authors have suggested that people with elevated negative affectivity and social inhibition, also known as type D personality (Denollet, 2005), might perceive greater threat and report stronger feelings of distress during ambiguous situations (Grynberg et al., 2012) and exhibit an increased risk of stress-related cardiovascular events (Denollet et al., 2006). Studies suggest that individuals with high social stress tend towards vigilance with regard to subliminal social threat cues but not subliminal physical threat cues (Helzer, Connor-Smith \& Reed, 2009). A general negative cognitive bias when coping with traumatic exposures is considered to be a risk factor for post-traumatic stress disorder (DiGangi et al., 2013). Traumatic life experiences have also been suggested to increase psychosis proneness via cognitive biases (Gawęda et al., 2018), such as jumping to conclusions ("not needing long to reach a conclusion"), belief inflexibility bias ("not needing to consider alternatives when making a decision"), attention to threat bias ("people cannot be trusted") and external attribution bias ("things go wrong because of other people"). Previous research exploring the response to social stress in a virtual reality environment suggests that there is an additive effect of separate cognitive biases on paranoid responses to social stress, with greater effects via attention to threat bias and external attribution bias (Pot-Kolder et al., 2018). Studies including patients with schizophrenia and acute delusions also indicate that patients under stress show an increased bias of jumping to conclusions (Moritz et al., 2015). Risk communication, defined by the World Health Organization as "the exchange of real-time information, advice and opinions between experts and people facing threats to their health, economic or social well-being", might lead to hoarding behaviour (Abrams \& Greenhawt, 2020). This risk communication has become more relevant in recent years, as social media networks are constantly increasing. Previous studies modelling the propagation of social responses during a disease outbreak (Fast et al., 2015), which include the hoarding of medical supplies, suggest that heightened social responses spread through the population via two mechanisms: 1) when a disease is novel to the region or is perceived as particularly threatening, media influence spreads concern through the population; 2) when communicating with their neighbours, agents are biased towards adopting the opinions of their more concerned neighbours rather than the most calm ones. 
465 Another threat to human society is digital misinformation, which has been suggested to be 466 related to the phenomenon called "echo chambers", leading to diffusion with a bandwagon effect 467 (Törnberg, 2018). Another problem of misinformation is that false news diffuses faster than true 468 news in social networks (Vosoughi, Roy \& Aral, 2018). The bandwagon effect does not apply 469 only to negative or threatening news. For instance, during the COVID-19 pandemic, the toilet 470 paper challenge spread over social media and was replicated by thousands of people. This

471

472

473

474

475

476

477

478

479

480

481

482

483

484

485

486

487

488

489

490

491

492

493

494

495

496

497

498

499

500

501

502

503

504 challenge, also known as the "10 Touch Challenge," was initially proposed by football players who tried to juggle a roll of toilet paper ten times with their feet, similar to how soccer players juggle soccer balls in training (White, 2020). Thousands of people uploaded their personal videos on the internet, which seemed to relieve the negative effects of the lockdown because most people ended their videos with a satisfied smile. Although it is unknown how long this positive psychological effect lasts, this conduct clearly reflects how the bandwagon effect contributed to the inadequate use of toilet paper during the COVID-19 pandemic.

\section{Stress worsens mental health and toilet paper hoarding (Mechanism \#3)}

Stress promotes the secretion of hormones (e.g., glucocorticoids, catecholamines) that are adaptive in the short term but that might promote pathophysiological processes over longer time periods, when they are secreted in excess or are dysregulated either by not being produced in sufficient amounts during periods of challenge or change or by not being turned off efficiently after the challenge (McEwen, 2001). Bruce McEwen coined the term allostatic load to define "the wear and tear on the body" as a result of the accumulation of chronic stress (McEwen, 1998). This model might be applied to most mental illnesses, including mood disorders (McEwen, 2003), psychotic disorders (Nugent et al., 2015) and anxiety disorders (Nolte et al., 2011).

Stressful and traumatic life events might trigger the onset of hoarding disorder, particularly for cases with a later onset (Tolin et al., 2010; Landau et al., 2011). Stress, mainly changes in relationships and interpersonal violence, are also associated with an exacerbation of hoarding behaviour (Tolin et al., 2010). Other studies point out that early life stress with insecure attachment (Danet \& Secouet, 2018; Crone et al., 2019) or low parental emotional warmth (Alonso et al., 2004) might play a role in the pathogenesis of hoarding behaviours. Traumatic life events are associated with a greater severity of hoarding symptoms, particularly in the clutter factor of compulsive hoarding (but not in the difficulty of discarding or acquisitioning) (Cromer, Schmidt \& Murphy, 2007). It has been suggested that the coexistence of traumatic experiences and inattention and hyperactivity symptoms could contribute to the difficulties of clutter and organisation reported by hoarders (Hartl et al., 2005). However, other experimental studies that have tested whether stress influences saving and acquiring behavioural tendencies in young adults (Shaw \& Timpano, 2016) have yielded unexpected results: participants in the stress condition saved and acquired fewer items than those in the control condition. As discussed by the authors of the previous study (Shaw \& Timpano, 2016), the laboratory stressor may not have been strong enough to increase saving and acquiring behavioural tendencies, and there is a need 
505 to conduct studies exploring the effects of acute stressors that are more similar to real-life

506 stressors experienced by individuals with hoarding (such as interpersonal conflict).

507 Intolerance to uncertainty has been proposed as a risk factor for hoarding behaviour (Wheaton et

508 al., 2016). Interestingly, recent studies exploring the role of intolerance to uncertainty in mental

509 well-being associated with the COVID-19 pandemic have reported that the combination of

510 rumination and fear of COVID-19 mediates the association between intolerance to uncertainty

511 and mental well-being (Satici et al., 2020). Intolerance to uncertainty is also a predictor of the

512 severity of hoarding symptoms in people with hoarding disorder (Worden et al., 2019). Many of

513 the recommended measures during the COVID-19 pandemic, such as washing and prevention of

514 contamination as well as the quarantine and nationwide lockdown, are thought to worsen

515 symptoms of patients with OCD or hoarding behaviours (Banerjee, 2020). Recent preliminary

516 studies suggest that OCD patients experienced worsened symptoms, particularly contamination

517 obsessions, during the COVID-19 pandemic (Davide et al., 2020).

518 Personality traits are also important moderators of the response to stressful situations,

519 particularly neuroticism, which appears to play a prominent role in the stress process (De Jong,

520 Van Sonderen \& Emmelkamp, 1999). People with high neuroticism report more exposure to

521 stressors (Bolger \& Schilling, 1991), higher perceived stress (Ebstrup et al., 2011; Kim et al.,

522 2016) and more inadequate coping strategies (Connor-Smith \& Flachsbart, 2007). People with

523 high neuroticism are also at greater risk for major depression and more sensitive to the

524 depressogenic effects of adversity resulting from exposure to stressful life events (Kendler, Kuhn

$525 \&$ Prescott, 2004). Neuroticism has also been associated with hoarding obsessions and

526 compulsions in a study that assessed personality with the NEO Personality Inventory-Revised

527 (LaSalle-Ricci et al., 2006). In this later study, hoarding was negatively correlated with

528 conscientiousness.

529 Regarding the COVID-19 pandemic, there are 4 studies that have analysed the role of personality

530 traits in toilet paper stockpiling. The first study by Garbe et al. (Garbe, Rau \& Toppe, 2020),

531 already mentioned in the Results section of the systematic review, reported that

532 conscientiousness was associated with toilet paper stockpiling, although emotionality had an

533 indirect effect on stockpiling by means of the threat of COVID-19. Another unpublished study

534 by Columbus (2020) conducted a survey in two samples of United Kingdom (UK) residents and

535 considered the stockpiling of foods or supplies. Approximately 36\% (sample 1) to 40\% (sample

536 2) of participants reported having bought more food or supplies than they usually did during the

537 preceding two weeks in response to the COVID-19 pandemic. Honesty-humility showed a

538 negative association with past stockpiling (sample 1) and a positive association with intentions to

539 refrain from stockpiling in the future (sample 2). The association between this personality

540 dimension and stockpiling was not mediated by beliefs about the shopping behaviour of others.

541 However, other studies suggest that viewing others experiencing stress creates a "contagious"

542 physiological stress response, with faster responses in people with high dispositional levels of

543 empathy (Dimitroff et al., 2017). A recent study (Zettler et al., 2020) explored the relationship

544 between 9 personality factors (including HEXACO and Big Five personality traits) and hoarding 
545 behaviour during the COVID-19 pandemic in five independent samples from two Western

546 European countries (overall sample: $\mathrm{N}=10.702$ ). In this study, honesty-humility and

547 agreeableness personality traits were negatively associated with hoarding behaviour.

548 Another study (Bentall et al., 2020) explored over-purchasing using data collected in the early

549 stages of the COVID-19 pandemic from two large population internet surveys in the UK and the

550 Republic of Ireland. People did not over-purchase toilet paper more than other common supplies

551 (e.g., tinned food or dried foods). However, this study did not specifically explore psychological

552 determinants of toilet paper hoarding or toilet paper over-purchasing when compared to other

553 items. Over-purchasing or hoarding was found to be positively associated with household

554 income, the presence of children at home, depression, anxiety, and mistrust of others or paranoia.

555 Regarding personality traits, conscientiousness was negatively associated with over-purchasing

556 in both samples. In the Irish sample, openness was also negatively associated with over-

557 purchasing in the Irish sample. In the UK sample, extraversion was associated with over-

558 purchasing, whereas neuroticism was negatively associated with over-purchasing. The variables

559 were found to predict approximately $34-36 \%$ of the variance of the model in the Republic of

560 Ireland and the UK.

561 One study (Bai, 2020) using two datasets from the UK (cross-sectional) and the United States

562 (longitudinal) tested whether people who endorse conspiracy theories may be particularly likely

563 to engage in panic buying behaviours during the COVID-19 pandemic. The study found a

564 positive relationship between conspiracy theory endorsement and stockpiling behaviour in both

565 samples. In the US sample, believing that COVID-19 is a real threat was another predictor of

566 stockpiling. Longitudinal analyses suggested that conspiracy theory endorsement was a predictor

567 of stockpiling behaviour in the future, even after controlling for self-reported baseline

568 stockpiling behaviours.

569 Psychoanalytical explanations for the hoarding of toilet paper might be formulated, such as a

570 form of regression to the anal stage allowing our ego to feel in control of an incontrollable

571 situation (COVID-19 pandemic) (Anghelou, 2020; Wood, 2020). As suggested by Freud, the

572 second stage of psychosexual development is the anal stage (typically occurring during the 2nd

573 year of life), in which the child's interest and sexual pleasure are focused on the expulsion and

574 retention of faeces and the sadistic instinct is linked to the desire to both possess and destroy the

575 object (American Psychological Association, 2020). Some authors (Güzel, 2020) think that panic

576 and restlessness over toilet paper was a response to political failure and that toilet panic hoarding

577 might be understood as a crude solution of the overwhelmed and fragmented subject in the

578 absence of a symbol of authority. Psychoanalytic theories also suggest that a regression to the

579 anal phase might occur in people with hoarding disorder, particularly when a traumatic or

580 emotionally distressing event happens (Camps \& Bigot, 2019).

581

582 Cultural aspects moderate the relationship between the COVID-19 pandemic and toilet paper

583 hoarding (Mechanism \#4) 
584 Some studies have explored whether hoarding disorder features differ across distinct cultural

585

586

587

588

589

590

591

592

593

594

595

596

597

598

599

600

601

602

603

604

605

606

607

608

609

610

611

612

613

614

615

616

617

618

619

620

621

622

623 settings. A study that included patients with hoarding disorder from the United Kingdom, Spain, Japan and Brazil (Nordsletten et al., 2018) indicates that the severity and core features of hoarding disorder as well as the cognitions and behaviours commonly associated with this condition are largely stable across cultures. One study comparing symptoms from the hoarding dimension in patients with OCD from China, the USA and Brazil reported a lower proportion of hoarding symptoms in the sample of patients from China (Li et al., 2009). However, another study found that hoarding disorder in East Asia is relatively common and symptomatically similar to that reported in Western countries (Wang et al., 2016).

Other studies have explored potential cultural differences in cognitive biases. In a study that examined the relationship between interpretation bias and social anxiety among Chinese adolescents, the results were similar to those found in Western samples (Yu et al., 2019). Although studies have not addressed whether there are differences in the social response to the COVID-19 pandemic by distinct countries or cultures, an indirect way to approach this question is to explore Google trend topics. In the Google trend topics by country for the word "toilet paper", Australia was the leading country (score of 100), followed by the USA (score of 74) and Canada (score of 42). The trend in the use of the search term "toilet paper" on Google was similar for these three countries and the United Kingdom (Figure 2, A-D), although a different pattern was observed for India (Figure 2E), another country in which English is an official language. As shown in Figure 2, most countries had a peak in March 2020, which coincides with the COVID-19 outbreaks in different countries and the implementation of lockdowns. The massive search for "toilet paper" decreased in a few weeks to previous levels. If we compare the Google search trends for "toilet paper" and "COVID", in most countries, the "COVID" term was always ranked above "toilet paper" in search interest (Figure S1), with the exception of Australia, such that in the first week of March, the interest in "toilet paper" was 20, clearly above interest in the term "COVID" (5).

In a previous study that explored panic buying of toilet paper (Keane \& Neal, 2020), an index of panic during the COVID-19 pandemic was created considering five terms: toilet paper, panic buying, hoarding, panic, and supermarket. For non-English-speaking countries, these terms were translated. Countries were grouped into three regions (Europe and North America; Asia [including Oceania]; and the rest of the world). Keane and Neal (Keane \& Neal, 2020) found significant heterogeneity between regions in the timing and severity of panic between January and April 2020. They also compared the peak panic indexes between countries: Italy (panic index of 0.15 on 22/3/2020, following the national lockdown on 20/3/2020); France (panic index of 0.083 on 16/3/2020, the same day of the announcement of their nationwide lockdown); United Kingdom (panic index of 0.18 on 22/3/2020, occurring in the same week of the announcement of internal restrictions, including school closings and restrictions on gatherings and movement); and Australia (panic index of 0.79 on $4 / 3 / 2020$; it was the country with the greatest speed of panic spread [as the panic index was 0.08 two days before, on 2/3/2020]). As there were no important policy announcements in Australia by this time (restrictions on gatherings were announced on 
$62413 / 3 / 2020$ ), it is difficult to explain this massive spike with these factors. The authors of the last 625 study concluded that their model could not explain this panic pattern in Australia. Other 626 countries with massive spikes that could not be easily explained were Japan, Taiwan and 627 Singapore. The study of Keane and Neal suggested that internal movement restrictions generate 628 considerable consumer panic in the short term, but the effect largely vanishes after a week to ten 629 days. Moreover, they also found a response of consumer panic to announcements of internal 630 movement restrictions in foreign countries.

631 A cultural aspect that is important to consider is the use of toilet paper by different countries.

632 Despite the global reduction in open defecation in the last two decades, which might be defined 633 as the lack of use of toilet facilities for defecation, there is still a substantial worldwide 634 proportion of people from rural areas in less economically developed countries who engage in 635 open defecation. For instance, World Bank data suggest that the prevalence of open defecation in 636 rural areas worldwide was $37.1 \%$ in 2000, with a reduction of up to $18.3 \%$ in 2017 (World Bank

637 Group, 2020a). This information points to possible differences in the use of toilet paper and 638 likely hoarding behaviour aiming at conserving this item in rural areas when compared to urban 639 areas, as only $1.5 \%$ of the population of urban areas continues to engage in open defecation 640 (World Bank Group, 2020b).

641 Toilet paper consumption differs by country. The estimated annual per capita toilet paper 642 consumption in selected countries in 2018 (obtained from Statista Consumer Market Outlook)

643 (Armstrong, 2020) describes the USA as the leading country (141 rolls and $12.7 \mathrm{~kg}$ ), followed by 644 Germany (134 rolls and $12.1 \mathrm{~kg}$ ) and the UK (127 rolls and $11.4 \mathrm{~kg})$. There might also be 645 differences in cleaning habits between people from different countries. For instance, data from a 646 WIN/Gallup International survey conducted in 2015 suggest that only 50\% of people in the 647 Netherlands wash their hands with soap and water after using the toilet, compared to $96 \%$ of 648 people in Bosnia and Herzegovina (Marian, 2015).

649

650

651

652

653

654

655

656

657

658

659

660

\section{Discussion}

Our study aimed to explore the potential contribution of the COVID-19 pandemic to toilet paper hoarding. Our systematic review highlights the scarcity of studies addressing this important topic, and we identified very little published data. We want to highlight the study by Garbe et al. (Garbe, Rau \& Toppe, 2020) as being unique because they added empirical data on the influence of the perceived threat of COVID-19 and personality traits (mainly conscientiousness) on several behavioural aspects related to toilet paper shopping and stockpiling. Other studies were focused on the hoarding of supplies (Columbus; Oosterhoff \& Palmer, 2020), and they were not specifically focused on toilet paper hoarding, such as the study by Garbe et al. (Garbe, Rau \& Toppe, 2020). The secondary outcome of our systematic review focused on mental health, and 661 the pathological use of toilet paper also underscores that this is an under-researched topic, as we 662 could identify only six case reports regarding OCD, suicide, homicide or pica, although the 
663 quality of the case reports was relatively good. The methodology of a realist review allowed the

664

665

666

667

668

669

670

671

672

673

674

675

676

677

678

679

680

681

682

683

684

685

686

687

688

689

690

691

692

693

694

695

696

697

698

699

700

701

702

study of potential mechanisms contributing to toilet paper hoarding in the COVID-19 pandemic.

\section{Potential mechanisms relating the COVID-19 pandemic to toilet paper hoarding}

Although the authors of a systematic review on gastrointestinal symptoms in COVID-19 (Miri et al., 2020) suggested that the coexistence of diarrhoea could explain the coronavirus panic buying of toilet rolls, this hypothesis has not been adequately tested in the literature. Moreover, the presence of diarrhoea or the prolonged dissemination of SARS-CoV-2 in the faeces were lesserknown characteristics of the disease at the beginning of the outbreak, when people were buying and hoarding toilet paper. Indeed, the knowledge that there might be faecal-oral transmission of SARS-CoV-2 might induce some people to increase the use of toilet paper, but it does not seem to be the main mechanism explaining the global shopping frenzy at supermarkets. The relatively low proportion of diarrhoea (approximately 12-13\%) found in people with COVID-19 infection does not seem to justify the global trends in shopping for toilet paper. Moreover, shopping for and hoarding of toilet paper appeared to be more intense in the first weeks following the COVID-19 outbreak all around the world, with a reduction in the following weeks. This generalised behaviour in stores seems to mimic the Google trend surge on the internet for the word "toilet paper" during March 2020 and was amplified by the national lockdowns in most but not all (e.g., Australia) countries (Keane \& Neal, 2020).

The mechanism linking social cognitive biases seems to contribute to hoarding behaviour more clearly than the gastrointestinal mechanism. The bandwagon effect is likely the most replicated bias in different countries, as this effect has been previously found to be associated with toilet paper buying (Malcom, 1974). The progressive increase in social networks also seems to have contributed to the fast and worldwide expansion of toilet paper hoarding due to this cognitive bias, with this behaviour being replicated in many countries. Other negative affect and interpretation biases might be linked to intolerance to uncertainty, a clinical characteristic that has been associated with hoarding behaviour (Wheaton et al., 2016). These biases might be even more important given the uncertainty of the COVID-19 situation (Koffman et al., 2020), as the SARS-CoV-2 virus is a new virus with much information to be discovered. Interestingly, the intolerance of uncertainty was associated with poorer mental well-being mediated by both the fear of COVID-19 and rumination (Satici et al., 2020).

Another question to be resolved is whether risk factors for toilet paper hoarding during the COVID-19 pandemic are shared with other hoarding behaviours. In this sense, one study pointed out that conscientiousness is a personality trait linked to toilet paper stockpiling during the COVID-19 pandemic (Garbe, Rau \& Toppe, 2020), whereas other studies including clinical samples of patients with hoarding symptoms found an opposite result (lower conscientiousness associated with hoarding symptoms) (LaSalle-Ricci et al., 2006). The different roles of conscientiousness in patients with hoarding symptoms and healthy people who hoarded toilet paper during the COVID-19 pandemic is an interesting finding that merits some discussion. Conscientiousness is a personality trait that implies being more efficient and organised, showing 
703

704

705

706

707

708

709

710

711

712

713

714

715

716

717

718

719

720

721

722

723

724

725

726

727

728

729

730

731

732

733

734

735

736

737

738

739

740

741

742

self-discipline that involves planned behaviour (Costa, McCrae \& Dye, 1991). This personality trait fits well with the idea that healthy people under a stressful situation (e.g., COVID-19 pandemic) might decide to buy and hoard toilet paper, particularly when news points to the possibility of a shortage of toilet paper (Schrotenboer, 2020). Although some studies have related conscientiousness with OCD (Rector et al., 2002; Inchausti, Delgado \& Prieto, 2015), other studies have found lower conscientiousness in OCD patients than in healthy controls (Hwang et al., 2012). Moreover, other studies suggest that there might exist differences based on the OCD phenotype: higher conscientiousness in comorbid tic-related OCD (Nestadt et al., 2009) and lower conscientiousness in a comorbid affective-related class (Nestadt et al., 2009) or with the presence of hoarding symptoms (LaSalle-Ricci et al., 2006; Samuels et al., 2008; Boerema et al., 2019). The different associations between conscientiousness and hoarding behaviour in nonclinical (higher conscientiousness) and clinical populations (low conscientiousness) is an intriguing finding, as the non-clinical study included people recruited during the COVID-19 pandemic (Garbe, Rau \& Toppe, 2020), whereas the clinical studies included patients with OCD (LaSalle-Ricci et al., 2006; Samuels et al., 2008; Boerema et al., 2019). Two studies found a negative association between honesty-humility and hoarding food and supplies (Columbus, 2020; Zettler et al., 2020). Although no previous studies have explored honesty-humility personality traits in clinical samples of patients with hoarding disorder, this personality trait is associated with trustworthiness (Thielmann \& Hilbig, 2015) and cooperation with others. People with hoarding symptoms show increased feelings of hostility in response to social exclusion (Mathes et al., 2019); therefore, it could be hypothesised that hoarders might have a reduced tendency to cooperate with others. It is notable that the two studies reporting associations between honesty-humility and hoarding behaviour during the COVID-19 pandemic (Columbus, 2020; Zettler et al., 2020) did not differentiate the subtype of stockpiled items when exploring the contribution of personality factors. In the study by Garbe et al. (2020), which was focused on toilet paper, honesty-humility was not associated with toilet paper stockpiling.

It is possible that hoarding of toilet paper is a distinct phenotype compared with hoarding other items, at least in terms of neurobiological/psychological pathophysiological pathways. This important question has yet to be answered, as studies focused on toilet paper hoarding are scarce. Future studies might examine whether personality traits linked to hoarding differ based on the subtype of hoarded items. Although speculative, it could be that toilet paper hoarding is a distinct subtype of hoarding disorder. To date, no definitive conclusions can be drawn, and more research needs to address this issue before assuming a different subtype of hoarding disorder or even considering the inclusion of a specifier for toilet paper hoarding in future diagnostic classifications (e.g., DSM-6). Another limitation of previous research on toilet paper hoarding during the COVID-19 pandemic is that most of the data come from surveys without the administration of diagnostic interviews by a psychiatrist or a clinical psychologist. Therefore, it is important to conduct clinical studies in the future to scrutinize the potential boundaries between mental illnesses and non-psychiatric conditions in the research of toilet paper hoarding. Although the diagnosis of a mental illness might require dysfunction criteria, the study of the 
743 boundaries of psychiatric illnesses may not be resolved until there is a detailed understanding of

744 the pathophysiology of the disorders (Kendell \& Jablensky, 2003).

745 Future studies also need to better address potential cultural differences that could explain some

746 differences in toilet paper hoarding between countries. An intriguing question is why Australians

747 were the leaders in panic buying. Tim Neal, who participated in a study about panic buying

748 during the COVID-19 pandemic (Keane \& Neal, 2020), pointed out that the Australian media's

749 coverage of hoarding could have contributed to the world-leading levels of panic (Zhou, 2020).

750 Other Asian countries, such as Japan, Taiwan and Singapore, that also had massive spikes that

751 could not be easily explained were found in the model developed by Keane and Neal (Keane \&

752 Neal, 2020). Shocking news from Asian countries was also reported early in the COVID

753 pandemic, including an armed robbery of toilet paper in Hong Kong (Ho-Him, 2020) or the

754 chaining of toilet paper rolls in public toilets in Japan (Acharya, 2020). Some authors have

755

756

757

758

759

760

761

762

763

764

765

766

767

768

769

770

771

772

773

774

775

776

777

778

779

780

781

782

suggested that the dense, close-knit networks of some countries (e.g., Singapore) make people more prone to adopt the fears and behaviours of the people around them (Bouffanais, 2020).

\section{Managing toilet paper hoarding: a proposed algorithm from the CATOTIM group}

The management of potential cases of toilet paper hoarding is a challenge for the clinician. The differential diagnosis of a patient with hoarding symptoms is quite complex because hoarding symptoms might be present in different psychiatric and neurological conditions (Pertusa et al., 2010) and because patients with hoarding disorder often underreport specific symptoms (DiMauro et al., 2013). Recent epidemiological studies indicate that the prevalence of hoarding disorder in the general population is $2.5 \%$ (confidence interval: $1.7-3.6 \%$ ), with similar prevalence rates for both males and females (Postlethwaite, Kellett \& Mataix-Cols, 2019). We have tried to integrate the main findings of our review and the personal expertise of the members of the Catalan Toilet Tissue Research Group in Mental Health (CATOTIM) that participated in this study in a proposed algorithm that is described in Figure 3. A validation study for this algorithm has not been included; therefore, our pilot algorithm for managing toilet paper hoarding should be considered a theoretical proposal. The generation of the algorithm was a dynamic process. Successive versions of the algorithm were created taking into account the findings of the systematic and realist reviews and the comments from all CATOTIM members. As shown in Figure 3, the first key question is to know whether there is an accumulation (hoarding) of toilet paper. For those cases with evident toilet paper hoarding, psychopathological assessment needs to first detect potential confusion or cognitive problems (attention deficits, memory loss). In that case, it is important to eliminate the possibility of neurological syndromes such as dementia that have been reported to be associated with hoarding symptoms in approximately 23-29\% of cases (Hwang et al., 1998; Mitchell et al., 2019). Patients suffering from delirium might have complex stereotyped movements and, rarely, the mimicking of a work pattern (occupational delirium) (Burns, Gallagley \& Byrne, 2004). In these situations, it is important to disregard intercurrent medical processes, and it might be necessary to perform blood and urine tests, CT or MRI brain scans, substance use studies, and/or cerebrospinal fluid analyses 
783 (in cases with fever). In those patients accumulating toilet paper who show amnesia of the 784 situation and alterations in personal identity, dissociative disorders including post-traumatic 785 stress disorder need to be considered. For this reason, inquiry about potential toilet-related 786 traumatic events may shed light on this diagnosis. In oriented patients, the presence of specific 787 symptoms might lead to specific diagnoses: auditory hallucinations in patients with 788 schizophrenia or schizoaffective disorders and specific delusions in patients with non-affective 789 (e.g., schizophrenia) or affective (bipolar disorder, psychotic depression) psychoses. For 790 instance, a patient suffering from major depression with psychotic features might hoard paper if 791 there are nihilistic or catastrophic delusional ideas (e.g., the belief that bad things are about to 792 happen, feelings of being rotten) (Rothschild, 2013).

793 In some cases, it is possible that people hoard paper to give it to others. In cases when there is a 794 long-standing need for the person to be taken care of and a fear of being abandoned or separated

795

796

797

798

799

800

801

802

803

804

805

806

807

808

809

810

811

812

813

814

815

816

817

818

819

820

821

822

from close individuals, the possibility of a dependent personality disorder needs to be considered. People with bipolar disorder with hypomanic symptoms might also hoard paper for making gifts to others, although the presence of a euphoric mood could also guide the diagnosis. A particularly important condition to be considered is OCD. Initially, hoarding symptoms were thought to be a feature of OCD, but in the last DSM-5, a distinct entity for compulsive hoarding was included. It is critical to explore other obsessive-compulsive symptoms (cleaning obsessions and washing compulsions, sexual/religious obsessions, aggressive obsessions with checking compulsions, symmetry obsessions with ordering compulsions) because their existence can guide the diagnosis to OCD when compared with a primary hoarding disorder without obsessivecompulsive symptoms (Pertusa et al., 2008). Notably, hoarding symptoms might be present in people with high neuroticism, particularly if they suffer from generalised anxiety disorder (Tolin et al., 2011) or obsessive-compulsive personality disorder (OCPD) (Mataix-Cols et al., 2010). If hoarding symptoms appear in people with social isolation and restricted interests, autism disorders and specific personality disorders (schizoid [indifference to social relationships, with a limited range of emotional expression and experience] and avoidant [feelings of extreme social inhibition, inadequacy, and sensitivity to negative criticism and rejection]) also need to be considered. In autism, hoarding symptoms are common (approximately $25 \%$ of cases) and are associated with internalizing and anxiety/depressive symptoms, externalizing behaviour, and attention problems (Storch et al., 2016).

In cases in which people have been hoarding for reselling toilet paper, antisocial personality traits could be driving the hoarding. There have been documented cases of people hoarding up to 4800 toilet paper rolls to resell them on eBay at a greater cost (Brook, 2020). This conduct during a pandemic shows some of the characteristics of an antisocial personality disorder (Black, 2015): disregard for right or wrong, deceit for exploitation of others, disrespect of others, and lack of empathy for others.

If pathological conditions are not clearly found, as already mentioned, it is important to consider the contribution of social cognitive biases (e.g., bandwagon effect) for inducing hoarding symptoms in non-clinical populations.

Peer) reviewing PDF | (2020:09:52545:1:2:NEW 26 Nov 2020) 
823 Sometimes there is excessive buying of toilet paper secondary to excessive use without hoarding

824 behaviour. Clinicians need to consider in these cases the potential medical causes for either

825 diarrhoea or polyuria, with specific tests depending upon the reported symptoms. As already

826 mentioned, in rare conditions, people might eat toilet paper secondary to pica (Chisholm \&

827 Martin, 1981; Fisher et al., 2014). In cases with pica, if hypozincaemia is observed,

828 supplementation with zinc might resolve the abnormal eating behaviour (Chisholm \& Martin,

829 1981). An excessive (pathological) use of toilet paper by OCD patients with contamination

830 obsession symptoms needs to be considered. In some cases with resistant OCD and excessive

831 wiping, tACS might be useful (Klimke et al., 2016). People with impulse-control disorders and

832 borderline personality disorder might also use toilet paper in excess due to a lack of inhibition

833 control.

834 Although in some cases there is no apparent hoarding or excessive use of toilet paper, it is

835 important to consider the pathological use of toilet paper due to psychopathological disturbances.

836 In people with bipolar disorder with a manic episode, spending sprees and bizarre gifts might

837 occur. In other cases, there could be surreptitious hoarding that was not easily observed in the

838 first assessment. This could arise in people with psychotic symptoms, particularly if there is

839 suspiciousness (e.g., paranoid personality disorder, psychotic disorders). In a patient with

840 depressive mood, suicidal ideation needs to be explored because toilet paper might be used as a

841 lethal mechanism for committing suicide (Sauvageau \& Yesovitch, 2006; Saint-Martin, Bouyssy

842 \& O'Byrne, 2007).

843 If there is no apparent psychopathology, the diagnosis might be reconsidered. However, a

844 previous step is to be sure that the individual has not participated in the toilet paper challenge. If

845 this is the case, it is probable that his/her conduct is driven by social cognitive biases (e.g.,

846 bandwagon effect).

847 Finally, it is also important to mention that under unusual circumstances, toilet paper hoarding

848 might be considered rational behaviour. In line with this, Laato et al. (2020) suggest that rational

849 decision-making processes might be affected in ill-defined, ambiguous, and unclear

850 circumstances, such as the period in which the COVID-19 virus spread rapidly in Europe during

851 the first wave (March 2020). As this study points out, the buying and stockpiling of toilet paper

852 might be considered a normal behaviour in some circumstances, such as preparing for self-

853 isolation. In these circumstances, defining pathological hoarding, when compared to excessive

854 stockpiling, can be a difficult task.

855

856 Clinical and ecological implications

857 Our study underscores the need to consider the pathological use and hoarding of toilet paper in

858 clinical practice, as this behaviour might have negative consequences for the functioning and

859 quality of life of people with or without serious mental illnesses. It is particularly important to

860 eliminate the possibility of psychiatric disorders that might be associated with toilet paper

861 hoarding and that might require specific treatments. This approach is a challenge for psychiatrists 
862 and clinical psychologists who need to consider potential comorbid medical conditions that could 863 also worsen this behaviour.

864 The potential contribution of social media to social cognitive biases (e.g., bandwagon effect) and 865 social-driven panic behaviours underscores the importance of managing news in the media and 866 avoiding disseminating fake news on the internet. To fight this issue, in April 2018, the European 867 Commission and representatives of online platforms, leading social networks, advertisers and the 868 advertising industry agreed on a self-regulatory Code of Practice to address the spread of online 869 disinformation and fake news (European Commission, 2020). Attached to the principles of this 870 Code of Practice is a step for most people using and working with social media in order to avoid 871 the negative psychological consequences of disseminating fake news.

872 Recent updated analysis from the Natural Resources Defense Council (NRDC) (Natural

873 Resources Defense Council, 2020) has reported the climate impacts caused by the "tree to toilet" 874 pipeline destroying the climate-critical Canadian boreal forest. Industry is thought to clear one 875 million acres of boreal forest each year (led by Brazil, Russia and Canada in terms of global 876 intact forest loss) in part to produce pulp that US tissue makers roll into toilet paper (Natural 877 Resources Defense Council, 2020). Environmentalists denounce this, as turning a tree into paper 878 requires more water than turning paper back into fibre, and many brands using tree pulp also use 879 polluting chlorine-based bleach to obtain greater whiteness (Kaufman, 2009). Another problem 880 for the sustainability of the planet is the continuously growing tendency to use toilet paper 881 (Crumbie, 2019). The worldwide revenue for the toilet paper segment from the tissue and 882 hygiene paper sector in 2019 was US\$ 83 billion, and it is expected to increase up to US\$ 100 883 billion by the year 2025 (Statista Consumer Market Outlook, 2020). An NRDC report (Skene, 884 2019) suggests that as the market for tissue grows around the world, recycled products and 885 alternative fibres will be the only way to accommodate increased demand without creating 886 further strain on indigenous peoples, the climate, and biodiversity.

887 For all these reasons, it is important that policy makers consider the potential negative impact of 888 toilet paper hoarding at both the individual and community levels, with potential harmful effects 889 to the planet. Therefore, it is recommended that policy makers develop strategies that promote 890 research on the causes and consequences of toilet paper hoarding.

891

892 Gaps in the literature and future directions

893 Although a previous survey (Garbe, Rau \& Toppe, 2020) suggested that the prevalence of toilet 894 paper hoarding was $17.2 \%$ for North Americans and 13.7\% for Europeans, more epidemiological 895 studies are needed to weigh the real prevalence of this hoarding behaviour and to administer 896 diagnostic interviews to eliminating the possibility of hoarding behaviour associated with 897 psychiatric disorders or stress-related "reactive" and "transitional" conduct. Longitudinal studies 898 could also help to explore whether these hoarding behaviours associated with the COVID-19 899 pandemic were only associated with the first COVID-19 outbreak or are repeated in subsequent 900 outbreaks. 
901 The psychological and neurobiological underpinnings of toilet paper hoarding are a fascinating 902 field to be explored. Future research might study whether or not the mechanisms that lead to 903 saving toilet paper are shared with other hoarded items. A particularly interesting hypothesis to 904 be tested relies on the contribution of personality traits, given the apparent different role of 905 conscientiousness in toilet paper hoarding during the COVID-19 pandemic (Garbe, Rau \& 906 Toppe, 2020) and in hoarding symptoms in people with OCD (LaSalle-Ricci et al., 2006; J.F. et 907 al., 2008). Research on neurobiological determinants might study the contribution of stress908 related biomarkers, including hypothalamic-pituitary-adrenal (HPA) axis hormones and 909 cytokines, given the implication of these biomarkers in stress-related pathologies (Soria et al., 910 2018; Russell \& Lightman, 2019). Future studies also might want to address the study of faeces, 911 as gut microbiota has emerged as a key player in the control of the HPA axis, especially during 912 stressful situations caused by real or perceived homeostatic challenges (Foster, Rinaman \& 913 Cryan, 2017). Neuroimaging studies might also explore the neural correlates of toilet paper 914 hoarding. Patients with hoarding disorder show higher dorsolateral prefrontal cortex (DLPFC) 915 activation during tests of executive functions than do patients with OCD (Hough et al., 2016). 916 OCD patients with prominent hoarding symptoms have also shown greater activation in the 917 bilateral anterior ventromedial prefrontal cortex (VMPFC) than do patients without hoarding 918 symptoms and healthy controls (An et al., 2009). As previous studies have shown dramatic 919 improvement in anus wiping of an OCD patient after brain stimulation with tACS targeting the 920 DLPFC, future studies might study the role of the prefrontal cortex in the pathogenesis of toilet 921 paper hoarding.

922

923

924

925

926

927

928

929

930

931

932

933

934

935

936

937

938

939

\section{Study limitations}

The main limitation of our study is the small number of studies included in our systematic review. A meta-analysis could not be performed for this reason, as in the protocol of our systematic review, we aimed to include a minimum of 5 studies with similar effect sizes for conducting a quantitative meta-analytical synthesis. We increased the number of publications with the realist review, and we also included grey literature, but the evidence generated from studies during the COVID-19 pandemic was particularly low. A negative publication bias on toilet paper hoarding is possible, as authors might avoid publishing articles dealing with toilet paper. Along these lines, negative outcomes associated with the pathological use of toilet paper (e.g., suicide cases secondary to toilet paper choking) might also be considered humiliating and be underreported in the scientific literature.

Finally, although we have proposed an algorithm for managing toilet paper hoarding or other pathological uses of toilet paper, it is important to emphasize that this algorithm has not been validated. Future studies might improve upon this limitation by testing and validating its application in clinical practice. If our algorithm is validated in future studies, it might be useful for psychiatrists and clinical psychologists who need to manage people with potential toilet paper hoarding behaviours. 
940 Although our study has several limitations, it is also the first realist review exploring potential 941 mechanisms that could explain in part the toilet paper hoarding experienced in many countries 942 during the COVID-19 pandemic. Our study allows the identification of gaps in the literature and 943 will help researchers to design and conduct future studies aiming to better understand the causes 944 and consequences of toilet paper hoarding in the general population and in people suffering from 945 mental illnesses.

946

\section{Conclusions}

948 The COVID-19 pandemic has been associated with a worldwide increase in hoarding 949 behaviours, with toilet paper being one of the most desired objects. Social media and social 950 cognitive biases seem to be major contributors to this hoarding behaviour and might explain 951 some differences in toilet paper hoarding between countries. Other mental health-related factors 952 are likely to be involved, such as the stressful situation of the COVID-19 pandemic, fear of 953 contagion, or particular personality traits (conscientiousness). Future studies might help to better characterise the phenotype of toilet paper hoarding and to explore psychological and neurobiological mechanisms underlying this behaviour.

956

957

958

959

960

961

962

963

964

\section{Acknowledgements}

This review is a proposal of the Catalan Toilet Tissue Research Group in Mental Health (CATOTIM), which is composed of psychiatrists and clinical psychologists interested in the study of the causes and consequences of pathological toilet paper use. All authors are members of the CATOTIM group. Current CATOTIM members are: Javier Labad, Alexandre GonzálezRodríguez, Jesús Cobo, Joaquím Puntí, Josep María Farré and Armand Guàrdia. As people were hoarding toilet paper amid the coronavirus pandemic, this study was driven by the interest in studying potential mechanisms linked to this behaviour that can cause distress to individuals.

965

966

\section{References}

967 Abrams EM, Greenhawt M. 2020. Risk Communication During COVID-19. Journal of Allergy

968 and Clinical Immunology: In Practice 8: 1791-1794. DOI: 10.1016/j.jaip.2020.04.012.

969 Acharya D. 2020. Amid The Coronavirus Outbreak, Public Toilets Chain Toilet Paper Rolls

970 Because People Are Stealing Them Like Crazy. Available at

971 https://mobygeek.com/features/japan-toilets-chian-toilet-paper-rolls-to-avoid-thieves-12251

972 Adhikari SP, Meng S, Wu YJ, Mao YP, Ye RX, Wang QZ, Sun C, Sylvia S, Rozelle S, Raat H, 973 Zhou H. 2020. Epidemiology, causes, clinical manifestation and diagnosis, prevention and 974 control of coronavirus disease (COVID-19) during the early outbreak period: A scoping review. 975 Infectious Diseases of Poverty 9:29. DOI: 10.1186/s40249-020-00646-x.

976 Alonso P, M. Menchón J, Mataix-Cols D, Pifarré J, Urretavizcaya M, Crespo JM, Jiménez S, 977 Vallejo G, Vallejo J. 2004. Perceived parental rearing style in obsessive-compulsive disorder: 
978 Relation to symptom dimensions. Psychiatry Research 127:267-278. DOI:

979 10.1016/j.psychres.2001.12.002.

980 American Psychological Association. 2020. Anal stage. APA Dictionary of Psychology.

981 Available at https://dictionary.apa.org/anal-stage

982 An SK, Mataix-Cols D, Lawrence NS, Wooderson S, Giampietro V, Speckens A, Brammer MJ, 983 Phillips ML. 2009. To discard or not to discard: The neural basis of hoarding symptoms in 984 obsessive-compulsive disorder. Molecular Psychiatry 14:318-331. DOI: 10.1038/sj.mp.4002129. 985 Anghelou A. 2020. Why everyone is buying toilet paper and how you can manage this period of 986 isolation due to Coronavirus. Available at https://www.neweurope.eu/article/why-is-everyone987 buying-toilet-paper-and-how-can-you-manage-this-period-of-isolation-due-to-the-coronavirus/ 988 Armstrong M. 2020. The U.S. Leads the World in Toilet Paper Consumption. Available at 989 https://www.statista.com/chart/15676/cmo-toilet-paper-consumption/

990 Badra M, Schulze L, Becker ES, Vrijsen JN, Renneberg B, Zetsche U. 2017. The association 991 between ruminative thinking and negative interpretation bias in social anxiety. Cognition and 992 Emotion 31:1234-1242. DOI: 10.1080/02699931.2016.1193477.

993 Bai, M. (2020). Who Bought All the Toilet Paper? Conspiracy Theorists Are More Likely to 994 Stockpile During the COVID-19 Pandemic. 2020. Retrieved from https://psyarxiv.com/z2g34/. 995 DOI: 10.31234/osf.io/z2g34

996 Banerjee DD. 2020. The other side of COVID-19: Impact on obsessive compulsive disorder 997 (OCD) and hoarding. Psychiatry Research 288: 112966. DOI: 10.1016/j.psychres.2020.112966. 998 Berg RC, Nanavati J. 2016. Realist Review: Current Practice and Future Prospects. Journal of 999 Research Practice 12:1-28.

1000 Black DW. 2015. The natural history of antisocial personality disorder. Canadian Journal of 1001 Psychiatry 60: 309-314. DOI: 10.1177/070674371506000703.

1002 Boerema YE, de Boer MM, van Balkom AJLM, Eikelenboom M, Visser HA, van Oppen P. 1003 2019. Obsessive compulsive disorder with and without hoarding symptoms: Characterizing 1004 differences. Journal of Affective Disorders 246: 652-658. DOI: 10.1016/j.jad.2018.12.115. 1005 Bolger N, Schilling EA. 1991. Personality and the Problems of Everyday Life: The Role of 1006 Neuroticism In Exposure and Reactivity to Daily Stressors. Journal of Personality 59: 355-386. 1007 DOI: $10.1111 /$ j.1467-6494.1991.tb00253.x.

1008 Bouffanais R. 2020. Hoarding toilet paper: The mystery of such panic buying explained. The 1009 Straits Times. Available at https://www.straitstimes.com/opinion/hoarding-toilet-paper-the1010 mystery-of-such-panic-buying-explained

1011 Brook B. 2020. Supermarket boss's blunt reply to toilet paper hoarder wanting refund.

1012 News.com.au. Available at https://www.news.com.au/finance/business/retail/supermarket-bosss1013 blunt-reply-to-toilet-paper-hoarder-wanting-refund/news-

1014 story/985cc7022ce371a71b7d86c3031e2ce5

1015 Buchholz K. 2020.Toilet Paper Producers Roll'ing in the Dough. Available at 1016 https://www.statista.com/chart/21327/rise-in-revenue-toilet-paper-selected-countries/ 
1017 Bulli F, Melli G, Carraresi C, Stopani E, Pertusa A, Frost RO. 2014. Hoarding behaviour in an 1018 Italian non-clinical sample. Behavioural and Cognitive Psychotherapy 42: 297-311. DOI:

1019 10.1017/S1352465812001105.

1020 Burns A, Gallagley A, Byrne J. 2004. Delirium. Journal of Neurology, Neurosurgery and

1021 Psychiatry 75: 362-367. DOI: 10.1136/jnnp.2003.023366.

1022 Camps FD, Bigot J Le. 2019. A psychoanalytical approach to diogenes syndrome.

1023 Psychoanalytic Review 106: 207-223. DOI: 10.1521/prev.2019.106.3.207.

1024 Chappelow J. 2019. Bandwagon effect. Available at

1025 https:/www.investopedia.com/terms/b/bandwagon-effect.asp

1026 Chen N, Zhou M, Dong X, Qu J, Gong F, Han Y, Qiu Y, Wang J, Liu Y, Wei Y, Xia J, Yu T,

1027 Zhang X, Zhang L. 2020c. Epidemiological and clinical characteristics of 99 cases of 2019 novel

1028 coronavirus pneumonia in Wuhan, China: a descriptive study. The Lancet 395(10223): 507-513

1029 DOI: 10.1016/S0140-6736(20)30211-7.

1030 Chen Q, Zheng Z, Zhang C, Zhang X, Wu H, Wang J, Wang S, Zheng C. 2020b. Clinical

1031 characteristics of 145 patients with corona virus disease 2019 (COVID-19) in Taizhou, Zhejiang,

1032 China. Infection 48: 543-551. DOI: 10.1007/s15010-020-01432-5.

1033 Chen Y, Chen L, Deng Q, Zhang G, Wu K, Ni L, Yang Y, Liu B, Wang W, Wei C, Yang J, Ye

1034 G, Cheng Z. 2020a. The Presence of SARS-CoV-2 RNA in Feces of COVID-19 Patients.

1035 Journal of medical virology 92: 833-840. DOI: 10.1002/jmv.25825.

1036 Cheung KS, Hung IFN, Chan PPY, Lung KC, Tso E, Liu R, Ng YY, Chu MY, Chung TWH,

1037 Tam AR, Yip CCY, Leung K-H, Fung AY-F, Zhang RR, Lin Y, Cheng HM, Zhang AJX, To

1038 KKW, Chan K-H, Yuen K-Y, Leung WK. 2020. Gastrointestinal Manifestations of SARS-CoV-

10392 Infection and Virus Load in Fecal Samples From a Hong Kong Cohort: Systematic Review and

1040 Meta-analysis. Gastroenterology 159: 81-95. DOI: 10.1053/j.gastro.2020.03.065.

1041 Chisholm JC, Martin HI. 1981. Hypozincemia, ageusia, dysosmia, and toilet tissue pica. Journal

1042 of the National Medical Association 73:163-164

1043 Columbus S. 2020. Who Hoards? Honesty-Humility, beliefs, and prosocial behaviour: A test on

1044 stockpiling during the COVID-19 pandemic. PsyArXiv Preprints. Available at

1045 https://psyarxiv.com/8e62v/. DOI: 10.31234/osf.io/8e62v.

1046 Connor-Smith JK, Flachsbart C. 2007. Relations Between Personality and Coping: A Meta-

1047 Analysis. Journal of Personality and Social Psychology 93: 1080-1107. DOI: 10.1037/0022-

1048 3514.93.6.1080.

1049 Costa PT, McCrae RR, Dye DA. 1991. Facet scales for agreeableness and conscientiousness: A

1050 revision of tshe NEO personality inventory. Personality and Individual Differences 12: 887-898.

1051 DOI: 10.1016/0191-8869(91)90177-D.

1052 Cromer KR, Schmidt NB, Murphy DL. 2007. Do traumatic events influence the clinical

1053 expression of compulsive hoarding? Behaviour Research and Therapy 45:2581-2592. DOI:

1054 10.1016/j.brat.2007.06.005.

1055 Crone C, Kwok C, Chau V, Norberg MM. 2019. Applying attachment theory to indecisiveness in

1056 hoarding disorder. Psychiatry Research. 273: 318-324. DOI: 10.1016/j.psychres.2019.01.055. 
1057 Crumbie A. 2019. Toilet Paper. Ethical Consumer product guide. Available at

1058 https://www.ethicalconsumer.org/home-garden/shopping-guide/toilet-paper

1059 D'Amico F, Baumgart DC, Danese S, Peyrin-Biroulet L. 2020. Diarrhea During COVID-19

1060 Infection: Pathogenesis, Epidemiology, Prevention, and Management. Clinical Gastroenterology

1061 and Hepatology 18:1663-1672. DOI: 10.1016/j.cgh.2020.04.001.

1062 Da Z, Engelberg J, Gao P. 2011. In Search of Attention. Journal of Finance 66: 1461-1499. DOI: 1063 10.1111/j.1540-6261.2011.01679.x.

1064 Danet M, Secouet D. 2018. Insecure attachment as a factor in hoarding behaviors in a non1065 clinical sample of women. Psychiatry Research 270: 286-292. DOI:

1066 10.1016/j.psychres.2018.09.053.

1067 Davide P, Andrea P, Martina O, Andrea E, Davide D, Mario A. 2020. The impact of the COVID-

106819 pandemic on patients with OCD: Effects of contamination symptoms and remission state 1069 before the quarantine in a preliminary naturalistic study. Psychiatry Research 291: 113213. DOI: 1070 10.1016/j.psychres.2020.113213.

1071 De Jong GM, Van Sonderen E, Emmelkamp PMG. 1999. A comprehensive model of stress. The 1072 roles of experienced stress and neuroticism in explaining the stress-distress relationship.

1073 Psychotherapy and Psychosomatics 68: 290-298. DOI: 10.1159/000012346.

1074 Denollet J, Pedersen SS, Vrints CJ, Conraads VM. 2006. Usefulness of type D personality in

1075 predicting five-year cardiac events above and beyond concurrent symptoms of stress in patients 1076 with coronary heart disease. American Journal of Cardiology 97:970-973. DOI:

1077 10.1016/j.amjcard.2005.10.035.

1078 Denollet J. 2005. DS14: Standard assessment of negative affectivity, social inhibition, and type

1079 D personality. Psychosomatic Medicine 67:89-97. DOI: 10.1097/01.psy.0000149256.81953.49.

1080 DiGangi JA, Gomez D, Mendoza L, Jason LA, Keys CB, Koenen KC. 2013. Pretrauma risk

1081 factors for posttraumatic stress disorder: A systematic review of the literature. Clinical

1082 Psychology Review 33: 728-744. DOI: 10.1016/j.cpr.2013.05.002.

1083 DiMauro J, Tolin DF, Frost RO, Steketee G. 2013. Do people with hoarding disorder under-

1084 report their symptoms? Journal of Obsessive-Compulsive and Related Disorders 2:130-136.

1085 DOI: 10.1016/j.jocrd.2013.01.002.

1086 Dimitroff SJ, Kardan O, Necka EA, Decety J, Berman MG, Norman GJ. 2017. Physiological

1087 dynamics of stress contagion. Scientific Reports 7: 6168. DOI: 10.1038/s41598-017-05811-1.

1088 Ebstrup JF, Eplov LF, Pisinger C, Jørgensen T. 2011. Association between the five factor

1089 personality traits and perceived stress: Is the effect mediated by general self-efficacy? Anxiety,

1090 Stress and Coping 24: 407-419. DOI: 10.1080/10615806.2010.540012.

1091 European Commission. 2020. Code of Practice on Disinformation. Available at

$1092 \mathrm{https} / /$ ec.europa.eu/digital-single-market/en/news/code-practice-disinformation

1093 Fast SM, González MC, Wilson JM, Markuzon N. 2015. Modelling the propagation of social

1094 response during a disease outbreak. Journal of the Royal Society Interface 12: 20141105. doi:

1095 10.1098/rsif.2014.1105. PMID: 25589575; PMCID: PMC4345477. 
1096 Fisher C, Laudenslager M, Thapar M, Rothstein K. 2014. A Case of Gastritis in a Patient With 1097 Paper Pica. American Journal of Gastroenterology 109: S272. DOI: 10.14309/00000434$1098201410002-00922$.

1099 Foster JA, Rinaman L, Cryan JF. 2017. Stress \& the gut-brain axis: Regulation by the 1100 microbiome. Neurobiology of Stress 7: 124-13. DOI: 10.1016/j.ynstr.2017.03.001.

1101 Garbe L, Rau R, Toppe T. 2020. Influence of perceived threat of Covid-19 and HEXACO 1102 personality traits on toilet paper stockpiling. PLOS ONE 15:e234232. DOI:

1103 10.1371/journal.pone.0234232.

1104 Gawęda $Ł$, Prochwicz K, Adamczyk P, Frydecka D, Misiak B, Kotowicz K, Szczepanowski R, 1105 Florkowski M, Nelson B. 2018. The role of self-disturbances and cognitive biases in the 1106 relationship between traumatic life events and psychosis proneness in a non-clinical sample. 1107 Schizophrenia Research 193: 218-224. DOI: 10.1016/j.schres.2017.07.023.

1108 Gluth S, Rieskamp J, Büchel C. 2012. Deciding when to decide: time-variant sequential 1109 sampling models explain the emergence of value-based decisions in the human brain. The 1110 Journal of Neuroscience 32: 10686-10698. DOI: 10.1523/JNEUROSCI.0727-12.2012.

1111 Goel S, Hofman JM, Lahaie S, Pennock DM, Watts DJ. 2010. Predicting consumer behavior 1112 with web search. Proceedings of the National Academy of Sciences of the United States of 1113 America 107:17486-17490. DOI: 10.1073/pnas.1005962107.

1114 Greenhalgh T, Schmid MB, Czypionka T, Bassler D, Gruer L. 2020. Face masks for the public 1115 during the covid-19 crisis. The BMJ 369:m1435. DOI: 10.1136/bmj.m1435.

1116 Grynberg D, Gidron Y, Denollet J, Luminet O. 2012. Evidence for a cognitive bias of

1117

1118

1119

1120

1121

1122

1123

1124

1125

1126

1127

1128

1129

1130

1131

1132

1133

1134

1135 interpretation toward threat in individuals with a Type D personality. Journal of Behavioral Medicine 35:95-102. DOI: 10.1007/s10865-011-9351-7.

Guan W, Ni Z, Hu Y, Liang W, Ou C, He J, Liu L, Shan H, Lei C, Hui DSC, Du B, Li L, Zeng G, Yuen KY, Chen R, Tang C, Wang T, Chen P, Xiang J, Li S, Wang JL, Liang Z, Peng Y, Wei L, Liu Y, Hu YH, Peng P, Wang JM, Liu J, Chen Z, Li G, Zheng Z, Qiu S, Luo J, Ye C, Zhu S, Zhong N. 2020. Clinical characteristics of coronavirus disease 2019 in China. The New England Journal of Medicine 382:1708-1720. DOI: 10.1056/NEJMoa2002032.

Güzel A. 2020. A brief reflection on losing and finding toilet paper. Psychodynamic Practice, 26: 215-220. DOI: $10.1080 / 14753634.2020 .1759290$

Han C, Duan C, Zhang S, Spiegel B, Shi H, Wang W, Zhang L, Lin R, Liu J, Ding Z, Hou X. 2020. Digestive Symptoms in COVID-19 Patients With Mild Disease Severity: Clinical Presentation, Stool Viral RNA Testing, and Outcomes. The American Journal of Gastroenterology 115: 916-923. DOI: 10.14309/ajg.0000000000000664.

Hartl TL, Duffany SR, Allen GJ, Steketee G, Frost RO. 2005. Relationships among compulsive hoarding, trauma, and attention-deficit/ hyperactivity disorder. Behaviour Research and Therapy 43: 269-476. DOI: 10.1016/j.brat.2004.02.002.

He Y, Wang Z, Li F, Shi Y. 2020. Public health might be endangered by possible prolonged discharge of SARS-CoV-2 in stool. Journal of Infection 80:e18-e19. DOI:

10.1016/j.jinf.2020.02.031. 
1136 Helzer EG, Connor-Smith JK, Reed MA. 2009. Traits, states, and attentional gates:

1137 Temperament and threat relevance as predictors of attentional bias to social threat. Anxiety,

1138 Stress and Coping 22: 57-76. DOI: 10.1080/10615800802272244.

1139 Henry BM, de Oliveira MHS, Benoit J, Lippi G. 2020. Gastrointestinal symptoms associated

1140 with severity of coronavirus disease 2019 (COVID-19): a pooled analysis. Internal and

1141 Emergency Medicine 15: 857-859. DOI: 10.1007/s11739-020-02329-9.

1142 Ho-Him C. 2020.Two arrested after armed gang makes run for toilet rolls in HK\$1,600 heist as

1143 coronavirus panic shows no signs of easing. Available at https://www.scmp.com/news/hong-

1144 kong/law-and-crime/article/3050907/armed-gang-steals-hk1000-toilet-paper-coronavirus

1145 Hough CM, Luks TL, Lai K, Vigil O, Guillory S, Nongpiur A, Fekri SM, Kupferman E,

1146 Mathalon DH, Mathews CA. 2016. Comparison of brain activation patterns during executive

1147 function tasks in hoarding disorder and non-hoarding OCD. Psychiatry Research - Neuroimaging

1148 255:50-59. DOI: 10.1016/j.pscychresns.2016.07.007.

1149 Huang C, Wang Y, Li X, Ren L, Zhao J, Hu Y, Zhang L, Fan G, Xu J, Gu X, Cheng Z, Yu T,

1150 Xia J, Wei Y, Wu W, Xie X, Yin W, Li H, Liu M, Xiao Y, Gao H, Guo L, Xie J, Wang G, Jiang

1151 R, Gao Z, Jin Q, Wang J, Cao B. 2020. Clinical features of patients infected with 2019 novel

1152 coronavirus in Wuhan, China. The Lancet 395: 497-506. DOI: 10.1016/S0140-6736(20)30183-5.

1153 Hwang JP, Tsai SJ, Yang CH, Liu KM, Lirng JF. 1998. Hoarding behavior in dementia: A

1154 preliminary report. American Journal of Geriatric Psychiatry 6: 285-259. DOI:

1155 10.1097/00019442-199800640-00003.

1156 Hwang JY, Shin YC, Lim SW, Park HY, Shin NY, Jang JH, Park HY, Kwon JS. 2012.

1157 Multidimensional Comparison of Personality Characteristics of the Big Five Model,

1158 Impulsiveness, and Affect in Pathological Gambling and Obsessive-Compulsive Disorder.

1159 Journal of Gambling Studies. 28: 351-362. DOI: 10.1007/s10899-011-9269-6.

1160 Inchausti F, Delgado AR, Prieto G. 2015. Obsessive-compulsive disorder and its relationship

1161 with disgust vulnerability and conscientiousness. Psicothema 27: 254-260. DOI:

1162 10.7334/psicothema2015.7.

1163 Jacob C, Hoffmann V, Olliges E, Haile A, Jacobi B, Steinkopf L, Lanz M, Tschoep M, Meissner

1164 K. 2017. Stress changes how we think - Psychophysiological evidence for the Stress-Induced

1165 Deliberation to Intuition (SIDI)-model. Psychoneuroendocrinology 83: 13. DOI:

1166 10.1016/j.psyneuen.2017.07.273.

1167 Jin X, Lian JS, Hu JH, Gao J, Zheng L, Zhang YM, Hao SR, Jia HY, Cai H, Zhang XL, Yu GD, 1168 Xu KJ, Wang XY, Gu JQ, Zhang SY, Ye CY, Jin CL, Lu YF, Yu X, Yu XP, Huang JR, Xu KL, 1169 Ni Q, Yu CB, Zhu B, Li YT, Liu J, Zhao H, Zhang X, Yu L, Guo YZ, Su JW, Tao JJ, Lang GJ, 1170 Wu XX, Wu WR, Qv TT, Xiang DR, Yi P, Shi D, Chen Y, Ren Y, Qiu YQ, Li LJ, Sheng J,

1171 Yang Y. 2020. Epidemiological, clinical and virological characteristics of 74 cases of

1172 coronavirus-infected disease 2019 (COVID-19) with gastrointestinal symptoms. Gut 69:1002-

1173 1009. DOI: 10.1136/gutjnl-2020-320926.

1174 Kaufman L. 2009. Mr. Whipple Left It Out: Soft Is Rough on Forests. The New York Times.

1175 Available at https://www.nytimes.com/2009/02/26/science/earth/26charmin.html 
1176 Keane MP, Neal T. 2020. Consumer Panic in the COVID-19 Pandemic. SSRN Electronic 1177 Journal. DOI: 10.2139/ssrn.3600018.

1178 Kendell R, Jablensky A. 2003. Distinguishing between the validity and utility of psychiatric 1179 diagnoses. American Journal of Psychiatry. 160: 4-12. DOI: 10.1176/appi.ajp.160.1.4.

1180 Kendler KS, Kuhn J, Prescott CA. 2004. The Interrelationship of Neuroticism, Sex, and Stressful 1181 Life Events in the Prediction of Episodes of Major Depression. American Journal of Psychiatry 1182 161: 631-636. DOI: 10.1176/appi.ajp.161.4.631.

1183 Kim ES, Chin BS, Kang CK, Kim NJ, Kang YM, Choi JP, Oh DH, Kim JH, Koh B, Kim SE, 1184 Yun NR, Lee JH, Kim JY, Kim Y, Bang JH, Song KH, Kim H Bin, Chung K hyun, Oh M don. 1185 2020. Clinical course and outcomes of patients with severe acute respiratory syndrome 1186 coronavirus 2 infection: A preliminary report of the first 28 patients from the korean cohort study on COVID-19. Journal of Korean Medical Science 35: e142. DOI: 10.3346/JKMS.2020.35.E142. indirect effects of five factor personality and gender on depressive symptoms mediated by perceived stress. PLOS ONE 11: e0154140. DOI: 10.1371/journal.pone.0154140. Kirk CP, Rifkin LS. 2020. I'll trade you diamonds for toilet paper: Consumer reacting, coping and adapting behaviors in the COVID-19 pandemic. Journal of Business Research 117: 124-131. DOI: 10.1016/j.jbusres.2020.05.028.

Klimke A, Nitsche MA, Maurer K, Voss U. 2016. Case Report: Successful Treatment of Therapy-Resistant OCD with Application of Transcranial Alternating Current Stimulation (tACS). Brain Stimulation 9: 463-465. DOI: 10.1016/j.brs.2016.03.005. Klopfenstein T, Kadiane-Oussou NJ, Royer PY, Toko L, Gendrin V, Zayet S. 2020. Diarrhea: An underestimated symptom in Coronavirus disease 2019. Clinics and Research in Hepatology and Gastroenterology 44: 282-283. DOI: 10.1016/j.clinre.2020.04.002. Knoll C. 2020. Panicked Shoppers Empty Shelves as Coronavirus Anxiety Rises. The New York

1203 buying.html

1204 Koffman J, Gross J, Etkind SN, Selman L. 2020. Uncertainty and COVID-19: how are we to 1205 respond? Journal of the Royal Society of Medicine 113: 211-216. DOI:

$1206 \quad 10.1177 / 0141076820930665$.

1207 Landau D, Iervolino AC, Pertusa A, Santo S, Singh S, Mataix-Cols D. 2011. Stressful life events 1208 and material deprivation in hoarding disorder. Journal of Anxiety Disorders 25: 192-202. DOI: 1209 10.1016/j.janxdis.2010.09.002.

1210 LaSalle-Ricci VH, Arnkoff DB, Glass CR, Crawley SA, Ronquillo JG, Murphy DL. 2006. The 1211 hoarding dimension of OCD: Psychological comorbidity and the five-factor personality model. 1212 Behaviour Research and Therapy 44: 1503-1512. DOI: 10.1016/j.brat.2005.11.009.

1213 Lawrence LM, Ciorciari J, Kyrios M. 2014. Relationships that compulsive buying has with 1214 addiction, obsessive-compulsiveness, hoarding, and depression. Comprehensive Psychiatry 1215 55:1137-1145. DOI: 10.1016/j.comppsych.2014.03.005. 
1216 Lechien JR, Chiesa-Estomba CM, De Siati DR, Horoi M, Le Bon SD, Rodriguez A, Dequanter 1217 D, Blecic S, El Afia F, Distinguin L, Chekkoury-Idrissi Y, Hans S, Delgado IL, Calvo-Henriquez 1218 C, Lavigne P, Falanga C, Barillari MR, Cammaroto G, Khalife M, Leich P, Souchay C, Rossi C, 1219 Journe F, Hsieh J, Edjlali M, Carlier R, Ris L, Lovato A, De Filippis C, Coppee F, Fakhry N, 1220 Ayad T, Saussez S. 2020. Olfactory and gustatory dysfunctions as a clinical presentation of mild1221 to-moderate forms of the coronavirus disease (COVID-19): a multicenter European study.

1222 European Archives of Oto-Rhino-Laryngology 277: 2251-2261. DOI: 10.1007/s00405-0201223 05965-1.

1224 Lei Z, Cao H, Jie Y, Huang Z, Guo X, Chen J, Peng L, Cao H, Dai X, Liu J, Li X, Zhu J, Xu W, 1225 Chen D, Gao Z, He JR, Lin BL. 2020. A cross-sectional comparison of epidemiological and 1226 clinical features of patients with coronavirus disease (COVID-19) in Wuhan and outside Wuhan, 1227 China. Travel Medicine and Infectious Disease. 35: 101664. DOI: 10.1016/j.tmaid.2020.101664. 1228 Leung H. 2020. Knife-Wielding Robbers in Hong Kong Steal 600 Rolls of Toilet Paper Amid 1229 Coronavirus Panic. Time. Available at https://time.com/5785146/hong-kong-toilet-paper1230 robbery-coronavirus/

1231 Lewis L. 2020. Coronavirus forces Japan to rethink its view of toilet roll. Financial Times.

1232 Available at https://www.ft.com/content/397bd2a4-5d35-11ea-b0ab-339c2307bcd4

1233 Li J, Wang X, Chen J, Zuo X, Zhang H, Deng A. 2020c. COVID-19 infection may cause ketosis 1234 and ketoacidosis. Diabetes, Obesity and Metabolism. DOI: 10.1111/dom.14057.

1235 Li L quan, Huang T, Wang Y qing, Wang Z ping, Liang Y, Huang T bi, Zhang H yun, Sun W, 1236 Wang Y. 2020b. COVID-19 patients' clinical characteristics, discharge rate, and fatality rate of 1237 meta-analysis. Journal of Medical Virology 92: 577-583. DOI: 10.1002/jmv.25757.

1238 Li XY, Dai WJ, Wu SN, Yang XZ, Wang HG. 2020a. The occurrence of diarrhea in COVID-19 1239

1240 patients. Clinics and Research in Hepatology and Gastroenterology 44: 284-285. DOI: 10.1016/j.clinre.2020.03.017.

1242 Li Y, Marques L, Hinton DE, Wang Y, Xiao ZP. 2009. Symptom dimensions in Chinese patients with obsessive-compulsive disorder. CNS Neuroscience and Therapeutics 15: 276-282. DOI: 10.1111/j.1755-5949.2009.00099.x. GC, Liu HG. 2020. Clinical characteristics of novel coronavirus cases in tertiary hospitals in Hubei Province. Chinese Medical Journal 133:1025-1031. DOI: 10.1097/CM9.0000000000000744.

Malcom AH. 1974. The "shortage" of bathroom tissue: a classic study in rumor. New York Times.

Marian J. 2015. Study Reveals Hand-Washing Habits of Europeans. Available at

1252 https://jakubmarian.com/a-study-reveals-how-many-europeans-wash-their-hands-with-soap/ Mataix-Cols D, Cullen S, Lange K, Zelaya F, Andrew C, Amaro E, Brammer MJ, Williams SC, Speckens A, Phillips ML. 2003. Neural correlates of anxiety associated with obsessivecompulsive symptom dimensions in normal volunteers. Biol Psychiatry 53:482-493. DOI: 10.1016/s0006-3223(02)01504-4. PMID: 12644353. 
1256 Mataix-Cols D, Frost RO, Pertusa A, Clark LA, Saxena S, Leckman JF, Stein DJ, Matsunaga H, 1257 Wilhelm S. 2010. Hoarding disorder: A new diagnosis for DSM-V? Depression and Anxiety 27: 1258 556-572. DOI: 10.1002/da.20693.

1259 Mathes BM, Kennedy GA, Cougle JR, Schmidt NB. 2019. An examination of the relationship 1260 between hoarding symptoms and hostility. Journal of Psychiatric Research 111: 121-127. DOI: 1261 10.1016/j.jpsychires.2019.01.025.

1262 McEwen BS. 1998. Stress, adaptation, and disease. Allostasis and allostatic load. Annals of the 1263 New York Academy of Sciences 840: 33-44. DOI: 10.1111/j.1749-6632.1998.tb09546.x. 1264 McEwen BS. 2001. From molecules to mind. Stress, individual differences, and the social 1265 environment. Annals of the New York Academy of Sciences 935: 42-9. DOI: 10.1111/j.17491266 6632.2001.tb03469.x.

1267 McEwen BS. 2003. Mood disorders and allostatic load. Biological Psychiatry 54:200-207. DOI: 1268 10.1016/S0006-3223(03)00177-X.

1269 Micalizzi L, Zambrotta NS, Bernstein MH. 2020. Stockpiling in the time of COVID-19. British 1270 Journal of Health Psychology. DOI: 10.1111/bjhp.12480.

1271 Miri SM, Roozbeh F, Omranirad A, Alavian SM. 2020. Panic of Buying Toilet Papers: A 1272 Historical Memory or a Horrible Truth? Systematic Review of Gastrointestinal Manifestations of 1273 COVID-19. Hepatitis Monthly 20: e102729. DOI: 10.5812/hepatmon.102729.

1274 Mitchell E, Tavares TP, Palaniyappan L, Finger EC. 2019. Hoarding and obsessive-compulsive 1275 behaviours in frontotemporal dementia: Clinical and neuroanatomic associations. Cortex 121: 1276 443-453. DOI: 10.1016/j.cortex.2019.09.012.

1277 Moher D, Liberati A, Tetzlaff J, Altman DG. 2009. Preferred reporting items for systematic 1278 reviews and meta-analyses: the PRISMA statement. BMJ 339:b2535-b2535. DOI:

1279 10.1136/bmj.b2535.

1280 Moritz S, Köther U, Hartmann M, Lincoln TM. 2015. Stress is a bad advisor. Stress primes poor 1281 decision making in deluded psychotic patients. European Archives of Psychiatry and Clinical 1282 Neuroscience 265: 461-469. DOI: 10.1007/s00406-015-0585-1.

1283 Murad MH, Sultan S, Haffar S, Bazerbachi F. 2018. Methodological quality and synthesis of 1284 case series and case reports. Evidence-Based Medicine 23: 60-63. DOI: 10.1136/bmjebm-20171285110853.

1286 Natural Resources Defense Council. 2020. Toilet Paper and Climate Change: NRDC's Updated 1287 "Issue With Tissue" Ranks Brands on Sustainability. 2020. Available at

1288 https://www.nrdc.org/media/2020/200618-20

1289 Nestadt G, Di CZ, Riddle MA, Grados MA, Greenberg BD, Fyer AJ, McCracken JT, Rauch SL, 1290 Murphy DL, Rasmussen SA, Cullen B, Pinto A, Knowles JA, Piacentini J, Pauls DL, Bienvenu 1291 OJ, Wang Y, Liang KY, Samuels JF, Roche KB. 2009. Obsessive-compulsive disorder:

1292 Subclassification based on co-morbidity. Psychological Medicine 39: 1491-1501. DOI:

1293 10.1017/S0033291708004753. 
1294 Nolte T, Guiney J, Fonagy P, Mayes LC, Luyten P. 2011. Interpersonal stress regulation and the 1295 development of anxiety disorders: An attachment-based developmental framework. Frontiers in 1296 Behavioral Neuroscience 5: 55. DOI: 10.3389/fnbeh.2011.00055.

1297 Nordsletten AE, Fernández de la Cruz L, Aluco E, Alonso P, López-Solà C, Menchón JM, 1298 Nakao T, Kuwano M, Yamada S, Fontenelle LF, Campos-Lima AL, Mataix-Cols D. 2018. A 1299 transcultural study of hoarding disorder: Insights from the United Kingdom, Spain, Japan, and 1300 Brazil. Transcultural Psychiatry 55: 261-285 . DOI: 10.1177/1363461518759203.

1301 Nordsletten AE, Reichenberg A, Hatch SL, Fernández De La Cruz L, Pertusa A, Hotopf M, 1302 Mataix-Cols D. 2013. Epidemiology of hoarding disorder. British Journal of Psychiatry 203: 1303 445-452. DOI: 10.1192/bjp.bp.113.130195.

1304 Nugent KL, Chiappelli J, Rowland LM, Hong LE. 2015. Cumulative stress pathophysiology in 1305 schizophrenia as indexed by allostatic load. Psychoneuroendocrinology 60:120-129. DOI: 1306 10.1016/j.psyneuen.2015.06.009.

1307 O'Connor N, Clark S. 2019. Beware bandwagons! The bandwagon phenomenon in medicine, 1308 psychiatry and management. Australasian Psychiatry 27: 603-606. DOI:

1309 10.1177/1039856219848829.

1310 Ong J, Young BE, Ong S. 2020. COVID-19 in gastroenterology: A clinical perspective. Gut 69: 1311 1144-1145. DOI: 10.1136/gutjnl-2020-321051.

1312 Oosterhoff B, Palmer CA. 2020. Attitudes and Psychological Factors Associated With News 1313 Monitoring, Social Distancing, Disinfecting, and Hoarding Behaviors Among US Adolescents 1314 During the Coronavirus Disease 2019 Pandemic. JAMA Pediatrics e201876 . DOI: 1315 10.1001/jamapediatrics.2020.1876.

1316 Pan L, Mu M, Yang P, Sun Y, Wang R, Yan J, Li P, Hu B, Wang J, Hu C, Jin Y, Niu X, Ping R, 1317 Du Y, Li T, Xu G, Hu Q, Tu L. 2020. Clinical characteristics of COVID-19 patients with 1318 digestive symptoms in Hubei, China: A descriptive, cross-sectional, multicenter study. American 1319 Journal of Gastroenterology 115: 766-773. DOI: 10.14309/ajg.0000000000000620.

1320 Pertusa A, Frost RO, Fullana MA, Samuels J, Steketee G, Tolin D, Saxena S, Leckman JF, 1321 Mataix-Cols D. 2010. Refining the diagnostic boundaries of compulsive hoarding: A critical 1322 review. Clinical Psychology Review 30: 371-386. DOI: 10.1016/j.cpr.2010.01.007.

1323 Pertusa A, Fullana MA, Singh S, Alonso P, Menchón JM, Mataix-Cols D. 2008. Compulsive 1324 hoarding: OCD symptom, distinct clinical syndrome, or both? American Journal of Psychiatry 1325 165: 1289-1298. DOI: 10.1176/appi.ajp.2008.07111730.

1326 Pidd H. 2020. UK supermarkets ration toilet paper to prevent stockpiling. The Guardian.

1327 Available at https://www.theguardian.com/world/2020/mar/08/coronavirus-stockpiling-

1328 supermarkets-toilet-paper-hand-gel

1329 Postlethwaite A, Kellett S, Mataix-Cols D. 2019. Prevalence of Hoarding Disorder: A systematic 1330 review and meta-analysis. Journal of Affective Disorders 256: 309-316. DOI:

1331 10.1016/j.jad.2019.06.004. 
1332 Pot-Kolder R, Veling W, Counotte J, Van Der Gaag M. 2018. Self-reported Cognitive Biases 1333 Moderate the Associations between Social Stress and Paranoid Ideation in a Virtual Reality 1334 Experimental Study. Schizophrenia Bulletin 44: 749-756. DOI: 10.1093/schbul/sbx119.

1335 Rector NA, Hood K, Richter MA, Michael Bagby R. 2002. Obsessive-compulsive disorder and 1336 the five-factor model of personality: Distinction and overlap with major depressive disorder.

1337 Behaviour Research and Therapy 40: 1205-1219. DOI: 10.1016/S0005-7967(02)00024-4. 1338 Riley DS, Barber MS, Kienle GS, Aronson JK, von Schoen-Angerer T, Tugwell P, Kiene H, 1339 Helfand M, Altman DG, Sox H, Werthmann PG, Moher D, Rison RA, Shamseer L, Koch CA, 1340 Sun GH, Hanaway P, Sudak NL, Kaszkin-Bettag M, Carpenter JE, Gagnier JJ. 2017. CARE 1341 guidelines for case reports: explanation and elaboration document. Journal of Clinical 1342 Epidemiology 89: 218-235. DOI: 10.1016/j.jclinepi.2017.04.026.

1343 Rothschild AJ. 2013. Challenges in the treatment of major depressive disorder with psychotic 1344 features. Schizophrenia Bulletin 39: 787-796. DOI: 10.1093/schbul/sbt046.

1345 Russell G, Lightman S. 2019. The human stress response. Nature Reviews Endocrinology 15: 1346 525-534. DOI: 10.1038/s41574-019-0228-0.

1347 Saint-Martin P, Bouyssy M, O’Byrne P. 2007. An unusual case of suicidal asphyxia by 1348 smothering. Journal of Forensic and Legal Medicine 14:39-41. DOI:

1349 10.1016/j.jcfm.2005.11.015.

1350 Saint-Martin P, Lefrancq T, Sauvageau A. 2012. Homicidal smothering on toilet paper: A case 1351 report. Journal of Forensic and Legal Medicine 19: 234-235. DOI: 10.1016/j.jflm.2011.12.032. 1352 Samuels JF, Bienvenu OJ, Pinto A, Murphy DL, Piacentini J, Rauch SL, Fyer AJ, Grados MA, 1353 Greenberg BD, Knowles JA, McCracken JT, Cullen B, Riddle MA, Rasmussen SA, Pauls DL, 1354 Liang KY, Hoehn-Saric R, Pulver AE, Nestadt G. 2008. Sex-specific clinical correlates of 1355 hoarding in obsessive-compulsive disorder. Behaviour Research and Therapy 46:1040-1046. DOI: 10.1016/j.brat.2008.06.005.

1357 Samuels JF, Bienvenu OJ, Pinto A, Murphy DL, Piacentini J, Rauch SL, Fyer AJ, Grados MA, 1358 Greenberg BD, Knowles JA, McCracken JT, Cullen B, Riddle MA, Rasmussen SA, Pauls DL, 1359 Liang KY, Hoehn-Saric R, Pulver AE, Nestadt G. 2008. Sex-specific clinical correlates of 1360 hoarding in obsessive-compulsive disorder. Behaviour Research and Therapy 46: 1040-1046 . 1361 DOI: 10.1016/j.brat.2008.06.005.

1362 Satici B, Saricali M, Satici SA, Griffiths MD. 2020. Intolerance of Uncertainty and Mental 1363 Wellbeing: Serial Mediation by Rumination and Fear of COVID-19. International Journal of 1364 Mental Health and Addiction. DOI: 10.1007/s11469-020-00305-0.

1365 Sauvageau A, Yesovitch R. 2006. Choking on toilet paper: an unusual case of suicide and a 1366 review of the literature on suicide by smothering, strangulation, and choking. The American 1367 Journal of Forensic Medicine and Pathology 27:173-174. DOI:

1368 10.1097/01.paf.0000203269.97907.a7.

1369 Schrotenboer B. 2020.Coronavirus and shopping for supplies: Getting to the bottom of the toilet 1370 paper shortage. USA Today. Available at 
1371 https://eu.usatoday.com/story/money/2020/04/08/coronavirus-shortage-where-has-all-the-toilet-

1372 paper-gone/2964143001/

1373 Shaw AM, Timpano KR. 2016. An Experimental Investigation of the Effect of Stress on Saving 1374 and Acquiring Behavioral Tendencies: The Role of Distress Tolerance and Negative Urgency.

1375 Behavior Therapy 47: 116-129 . DOI: 10.1016/j.beth.2015.10.003.

1376 Sim K, Chua HC, Vieta E, Fernandez G. 2020. The anatomy of panic buying related to the 1377 current COVID-19 pandemic. Psychiatry Research 288:113015. DOI:

1378 10.1016/j.psychres.2020.113015.

1379 Skene J. 2019. The issue with tissue: how americans are flushing forests down the toilet. Natural 1380 Resources Defense Council (NRDC) Report. Available at

1381 https://www.nrdc.org/sites/default/files/issue-tissue-how-americans-are-flushing-forests-down1382 toilet-report.pdf

1383 Smith K, Bryant RA. 2000. The generality of cognitive bias in acute stress disorder. Behaviour

1384 Research and Therapy 38: 709-715 DOI: 10.1016/S0005-7967(99)00096-0.

1385 Smyth R. 2012. Bum Fodder: An Absorbing History of Toilet Paper. London: Souvenir Press

1386 Limited.

1387 Soria V, Uribe J, Salvat-Pujol N, Palao D, Menchón JM, Labad J. 2018.

1388 Psychoneuroimmunology of mental disorders. Revista de Psiquiatria y Salud Mental 11:115-

1389 124. DOI: 10.1016/j.rpsm.2017.07.006.

1390 Statista Consumer Market Outlook. 2020. Tissue and Hygiene Paper Report 2020 - Toilet Paper.

1391 Available at https://www.statista.com/study/48850/tissue-and-hygiene-paper-report-toilet-paper/

1392 Steketee G, Frost R. 2003. Compulsive hoarding: Current status of the research. Clinical

1393 Psychology Review 23: 905-927. DOI: 10.1016/j.cpr.2003.08.002.

1394 Storch EA, Nadeau JM, Johnco C, Timpano K, McBride N, Jane Mutch P, Lewin AB, Murphy

1395 TK. 2016. Hoarding in Youth with Autism Spectrum Disorders and Anxiety: Incidence, Clinical

1396 Correlates, and Behavioral Treatment Response. Journal of Autism and Developmental

1397 Disorders 46: 1602-1612. DOI: 10.1007/s10803-015-2687-z.

1398 The Lancet. 1869. Notes, Short Comments, and Answers to Correspondents: Medicated paper.

1399 Lancet 94:531.

1400 Thielmann I, Hilbig BE. 2015. The Traits One Can Trust: Dissecting Reciprocity and Kindness

1401 as Determinants of Trustworthy Behavior. Personality and Social Psychology Bulletin 41: 1523-

1402 1536. DOI: $10.1177 / 0146167215600530$.

1403 Tolin DF, Meunier SA, Frost RO, Steketee G. 2010. Course of compulsive hoarding and its

1404 relationship to life events. Depression and Anxiety 27: 829-838 . DOI: 10.1002/da.20684.

1405 Tolin DF, Meunier SA, Frost RO, Steketee G. 2011. Hoarding among patients seeking treatment

1406 for anxiety disorders. Journal of Anxiety Disorders 25: 43-48. DOI:

1407 10.1016/j.janxdis.2010.08.001.

1408 Törnberg P. 2018. Echo chambers and viral misinformation: Modeling fake news as complex

1409 contagion. PLoS ONE 13: e0203958. DOI: 10.1371/journal.pone.0203958. 
1410 Van Bockstaele B, Notebaert L, Salemink E, Clarke PJF, MacLeod C, Wiers RW, Bögels SM.

1411

1412

1413

1414

1415

1416

1417

1418

1419

1420

1421

1422

1423

1424

1425

1426

1427

1428

1429

1430

1431

1432

1433

1434

1435

1436

1437

1438

1439

1440

1441

1442

1443

1444

1445

1446

1447

1448

1449

2019. Effects of interpretation bias modification on unregulated and regulated emotional

reactivity. Journal of Behavior Therapy and Experimental Psychiatry 64: 123-132. DOI:

10.1016/j.jbtep.2019.03.009.

van Doremalen N, Bushmaker T, Morris DH, Holbrook MG, Gamble A, Williamson BN, Tamin

A, Harcourt JL, Thornburg NJ, Gerber SI, Lloyd-Smith JO, de Wit E, Munster VJ. 2020. Aerosol and Surface Stability of SARS-CoV-2 as Compared with SARS-CoV-1. The New England

Journal of Medicine 382:1564-1567. DOI: 10.1056/NEJMc2004973.

Vogel B, Trotzke P, Steins-Loeber S, Schäfer G, Stenger J, De Zwaan M, Brand M, Müller A. 2019. An experimental examination of cognitive processes and response inhibition in patients seeking treatment for buying-shopping disorder. PLoS ONE 14:e0212415 . DOI:

10.1371/journal.pone.0212415.

Vosoughi S, Roy D, Aral S. 2018. The spread of true and false news online. Science 359:11461151. DOI: $10.1126 /$ science.aap9559.

Wang W, Xu Y, Gao R, Lu R, Han K, Wu G, Tan W. 2020c. Detection of SARS-CoV-2 in Different Types of Clinical Specimens. JAMA - Journal of the American Medical Association 323: 1843-1844. DOI: 10.1001/jama.2020.3786.

Wang X, Fang J, Zhu Y, Chen L, Ding F, Zhou R, Ge L, Wang F, Chen Q, Zhang Y, Zhao Q. 2020a. Clinical characteristics of non-critically ill patients with novel coronavirus infection (COVID-19) in a Fangcang Hospital. Clinical Microbiology and Infection 26:1063-1068. DOI: 10.1016/j.cmi.2020.03.032.

Wang X, Liu W, Zhao J, Lu Y, Wang X, Yu C, Hu S, Shen N, Liu W, Sun Z, Li W. 2020 b. Clinical characteristics of 80 hospitalized frontline medical workers infected with COVID-19 in Wuhan, China. Journal of Hospital Infection 105: 399-403. DOI: 10.1016/j.jhin.2020.04.019. Wang Z, Wang Y, Zhao Q, Jiang K. 2016. Is the DSM-5 hoarding disorder diagnosis valid in China? Shanghai Archives of Psychiatry 28: 103-105. DOI: 10.11919/j.issn.1002-0829.215054. Wei XS, Wang X, Niu YR, Ye LL, Peng WB, Wang ZH, Yang WB, Yang BH, Zhang JC, Ma WL, Wang XR, Zhou Q. 2020. Diarrhea is associated with prolonged symptoms and viral carriage in COVID-19. Clinical Gastroenterology and Hepatology 18: 1753-1759.e2. DOI: 10.1016/j.cgh.2020.04.030.

Wells G, Shea B, O’Connell D, Peterson J, Welch V, Losos M, Tugwell P. 2012. The NewcastleOttawa Scale (NOS) for assessing the quality if nonrandomized studies in meta-analyses.

Available at http://www.ohri.ca/programs/clinical_epidemiology/oxford.asp. DOI: $10.2307 / 632432$.

Wheaton MG, Abramowitz JS, Jacoby RJ, Zwerling J, Rodriguez CI. 2016. An investigation of the role of intolerance of uncertainty in hoarding symptoms. Journal of Affective Disorders 193: 208-214. DOI: 10.1016/j.jad.2015.12.047.

White J. 2020. Lionel Messi takes on '10-touch toilet paper challenge' during coronavirus lockdown. Available at https://www.scmp.com/sport/football/article/3076057/lionel-messi-takes10-touch-toilet-paper-challenge-during

Peer) reviewing PDF | (2020:09:52545:1:2:NEW 26 Nov 2020) 
1450 WHO Coronavirus Disease (COVID-19) Dashboard. Available at https://covid19.who.int/

1451

1452

1453

1454

1455

1456

1457

1458

1459

1460

1461

1462

1463

1464

1465

1466

1467

1468

1469

1470

1471

1472

1473

1474

1475

1476

1477

1478

1479

1480

1481

1482

1483

1484

1485

1486

1487

1488
Wong G, Greenhalgh T, Westhorp G, Buckingham J, Pawson R. 2013. RAMESES publication standards: Realist syntheses. BMC Medicine 11:21. DOI: 10.1186/1741-7015-11-21. Gastroenterology and Hepatology. 35: 744-748. DOI: 10.1111/jgh.15047.

Wood KA. 2020.A Psychoanalysis of Toilet Paper and Freudian Wisdom in the Coronapocalypse. Available at https://medium.com/@kristiewood/a-psychoanalysis-of-toilet-paperfreudian-wisdom-in-the-corona-pocalypse-e664f2c2e3c6 Worden B, Levy HC, Das A, Katz BW, Stevens M, Tolin DF. 2019. Perceived emotion regulation and emotional distress tolerance in patients with hoarding disorder. Journal of Obsessive Compulsive and Related Disorders 22: 100441. DOI: 10.1016/j.jocrd.2019.100441. World Bank Group. 2000a. People practicing open defecation, rural (\% of rural population). Available at https://data.worldbank.org/indicator/SH.STA.ODFC.RU.ZS World Bank Group. 2000b. People practicing open defecation, urban (\% of urban population). Available at https://data.worldbank.org/indicator/SH.STA.ODFC.UR.ZS Worobey M, Cox J, Gill D. 2019. The origins of the great pandemic. Evolution, Medicine and Public Health 2019: 18-25. DOI: 10.1093/emph/eoz001.

Xiao F, Tang M, Zheng X, Liu Y, Li X, Shan H. 2020. Evidence for Gastrointestinal Infection of SARS-CoV-2. Gastroenterology 158: 1831-1833.e3. DOI: 10.1053/j.gastro.2020.02.055. Xu XW, Wu XX, Jiang XG, Xu KJ, Ying LJ, Ma CL, Li SB, Wang HY, Zhang S, Gao HN, Sheng JF, Cai HL, Qiu YQ, Li LJ. 2020b. Clinical findings in a group of patients infected with the 2019 novel coronavirus (SARS-Cov-2) outside of Wuhan, China: Retrospective case series. BMJ 368: m792. DOI: 10.1136/bmj.m606.

Xu Y, Li X, Zhu B, Liang H, Fang C, Gong Y, Guo Q, Sun X, Zhao D, Shen J, Zhang H, Liu H, Xia H, Tang J, Zhang K, Gong S. 2020a. Characteristics of pediatric SARS-CoV-2 infection and potential evidence for persistent fecal viral shedding. Nature Medicine 26: 502-505. DOI: 10.1038/s41591-020-0817-4.

Yeo C, Kaushal S, Yeo D. 2020. Enteric involvement of coronaviruses: is faecal-oral transmission of SARS-CoV-2 possible? The Lancet Gastroenterology and Hepatology 5: 335337 . DOI: 10.1016/S2468-1253(20)30048-0.

Yu M, Westenberg PM, Li W, Wang J, Miers AC. 2019. Cultural evidence for interpretation bias as a feature of social anxiety in Chinese adolescents. Anxiety, Stress and Coping 32: 376-386 DOI: 10.1080/10615806.2019.1598556.

Yu R. 2016. Stress potentiates decision biases: A stress induced deliberation-to-intuition (SIDI) model. Neurobiology of Stress 3: 83-95. DOI: 10.1016/j.ynstr.2015.12.006.

Zhang H, Li HB, Lyu JR, Lei XM, Li W, Wu G, Lyu J, Dai ZM. 2020a. Specific ACE2

expression in small intestinal enterocytes may cause gastrointestinal symptoms and injury after 2019-nCoV infection. International Journal of Infectious Diseases 96: 19-24. DOI:

10.1016/j.ijid.2020.04.027. 
1489 Zhang J, Liu P, Wang M, Wang J, Chen J, Yuan W, Li M, Xie Z, Dong W, Li H, Zhao Y, Wan 1490 L, Chu T, Wang L, Zhang H, Tao T, Ma J. 2020b. The clinical data from 19 critically ill patients 1491 with coronavirus disease 2019: a single-centered, retrospective, observational study. Journal of 1492 Public Health. DOI: 10.1007/s10389-020-01291-2.

1493 Zhao XY, Xu XX, Yin H Sen, Hu QM, Xiong T, Tang YY, Yang AY, Yu BP, Huang ZP. 2020. 1494 Clinical characteristics of patients with 2019 coronavirus disease in a non-Wuhan area of Hubei 1495 Province, China: A retrospective study. BMC Infectious Diseases. DOI: 10.1186/s12879-0201496 05010-w.

1497 Zhou N. 2020. Off the chart: Australians were world leaders in panic buying, beating UK and 1498 Italy. The Guardian.

1499 Zhu J, Ji P, Pang J, Zhong Z, Li H, He C, Zhang J, Zhao C. 2020. Clinical characteristics of 1500 3,062 COVID-19 patients: a meta-analysis. Journal of Medical Virology. DOI:

$1501 \quad 10.1002 /$ jmv.25884. 


\section{Table 1 (on next page)}

CMO scheme of the realist review. 


\section{Context}

COVID-19 pandemic
Mechanisms

Outcome

M1. COVID-19 disease is associated with diarrhoea (or polyuria), which contributes to the panic buying and toilet paper hoarding

M2. Social cognitive biases and social media are facilitators of toilet paper hoarding in the general population

M3. The COVID-19 pandemic is a stressful event that causes the exacerbation of mental illnesses and hoarding behaviours leading to toilet paper hoarding

M4. Cultural aspects moderate the relationship between the COVID-19 pandemic and toilet paper hoarding, with differences between countries 
Table 2 (on next page)

Main characteristics of case reports included in the Systematic Review $(n=6)$ 
1 Table 2. Main characteristics of case reports included in the Systematic Review $(n=6)$

\begin{tabular}{|c|c|c|c|c|c|c|c|c|c|c|}
\hline \multirow[b]{2}{*}{ Case } & \multirow[b]{2}{*}{$\begin{array}{l}\text { Author, year of } \\
\text { publication }\end{array}$} & \multirow[b]{2}{*}{$\begin{array}{c}\text { Age } \\
\text { (y.o) }\end{array}$} & \multirow[b]{2}{*}{ Gender } & \multirow[b]{2}{*}{$\begin{array}{l}\text { Substance } \\
\text { use }\end{array}$} & \multirow{2}{*}{$\begin{array}{c}\text { Comorbid } \\
\text { psychiatric } \\
\text { diagnosis }\end{array}$} & \multirow[b]{2}{*}{ Treatment } & \multirow[b]{2}{*}{$\begin{array}{c}\text { Primary outcome (toilet } \\
\text { paper) }\end{array}$} & \multirow[b]{2}{*}{$\begin{array}{l}\text { Secondary } \\
\text { outcomes }\end{array}$} & \multicolumn{2}{|c|}{$\begin{array}{c}\text { Checklist CARE } \\
\text { guidelines }\end{array}$} \\
\hline & & & & & & & & & $\begin{array}{l}\text { Completed } \\
\text { items }\end{array}$ & $\begin{array}{c}\text { Missing } \\
\text { sub-items }{ }^{*}, \#\end{array}$ \\
\hline 1 & $\begin{array}{l}\text { Klimke et al., } \\
2016\end{array}$ & 17 & Man & NR & OCD & $\begin{array}{l}\text { tACS, lorazepam } \\
0.5 \mathrm{mg} \text { day, }\end{array}$ & $\begin{array}{l}\text { Before treatment: use of } \\
10 \text { rolls of toilet paper } \\
\text { After treatment ( } 2 \\
\text { stimulations): } 1 \text { roll of } \\
\text { toilet paper }\end{array}$ & None & $8 / 13$ & $\begin{array}{l}5 \mathrm{c}, 5 \mathrm{~d}, 6,7 \\
8 \mathrm{a}, 8 \mathrm{~b}, 10 \mathrm{c}\end{array}$ \\
\hline 2 & $\begin{array}{l}\text { Sauvageau and } \\
\text { Yesovitch } 2006\end{array}$ & 58 & Man & NR & Schizophrenia & NR & No hoarding behaviour & $\begin{array}{c}\text { Suicidal } \\
\text { asphyxia by } \\
\text { toilet paper }\end{array}$ & $12 / 13$ & $5 c, 5 d$ \\
\hline 3 & $\begin{array}{l}\text { Saint-Martin et } \\
\text { al., } 2007\end{array}$ & 30 & Man & NR & BPD & $\begin{array}{l}\text { Psychotropic } \\
\text { drugs: } \\
\text { antidepressant, } \\
\text { tranquilizers and } \\
\text { conventional } \\
\text { antipsychotics }\end{array}$ & No hoarding behaviour & $\begin{array}{c}\text { Suicidal } \\
\text { asphyxia by } \\
\text { toilet paper } \\
\text { ingurgitation }\end{array}$ & $12 / 13$ & $5 c, 5 d$ \\
\hline 4 & $\begin{array}{l}\text { Saint-Martin et } \\
\text { al., } 2012\end{array}$ & 91 & Woman & NR & $\begin{array}{l}\text { Alzheimer's } \\
\text { disease }\end{array}$ & NA & No hoarding behaviour & $\begin{array}{l}\text { Homicidal } \\
\text { asphyxia by } \\
\text { toilet paper }\end{array}$ & $12 / 13$ & $5 c, 5 d$ \\
\hline 5 & $\begin{array}{l}\text { Fisher et al., } \\
2014\end{array}$ & 30 & Man & NR & Pica & NR & No hoarding behaviour & $\begin{array}{l}\text { Gastritis by toilet } \\
\text { paper ingestion } \\
\text { (Pica) }\end{array}$ & $10 / 13$ & $5 \mathrm{~d}, 7,10 \mathrm{c}$ \\
\hline 6 & $\begin{array}{l}\text { Chisholm and } \\
\text { Martin, } 1981\end{array}$ & 37 & Woman & NR & Pica & $\begin{array}{l}\text { Zinc and ferrous } \\
\text { sulfate }\end{array}$ & No hoarding behaviour & $\begin{array}{l}\text { Pica by toilet } \\
\text { paper ingestion }\end{array}$ & $12 / 13$ & $5 \mathrm{c}$ \\
\hline
\end{tabular}

3 *Checklist items from CARE guidelines include: 1, 2, 3a, 3b, 3c, 3d, 4, 5a, 5b, 5c, 5d, 6, 7, 8a, 8b, 8c, 8d, 9a, 9b, 9c, 10a, 10b, 10c, 10d, 11a, 11b, 11c, 11d, 12, 413. 
5 \# Items that are not applicable for the case report are not included in this section.

6 Abbreviations: BDP, Borderline Personality Disorder; OCD, Obsessive Compulsive Disorder; NA, Not applicable; NR, not reported; tACS, 7 transcranial alternating current stimulation; y.o., years old; 
Figure 1

PRISMA flow diagram of the studies included in the systematic review.

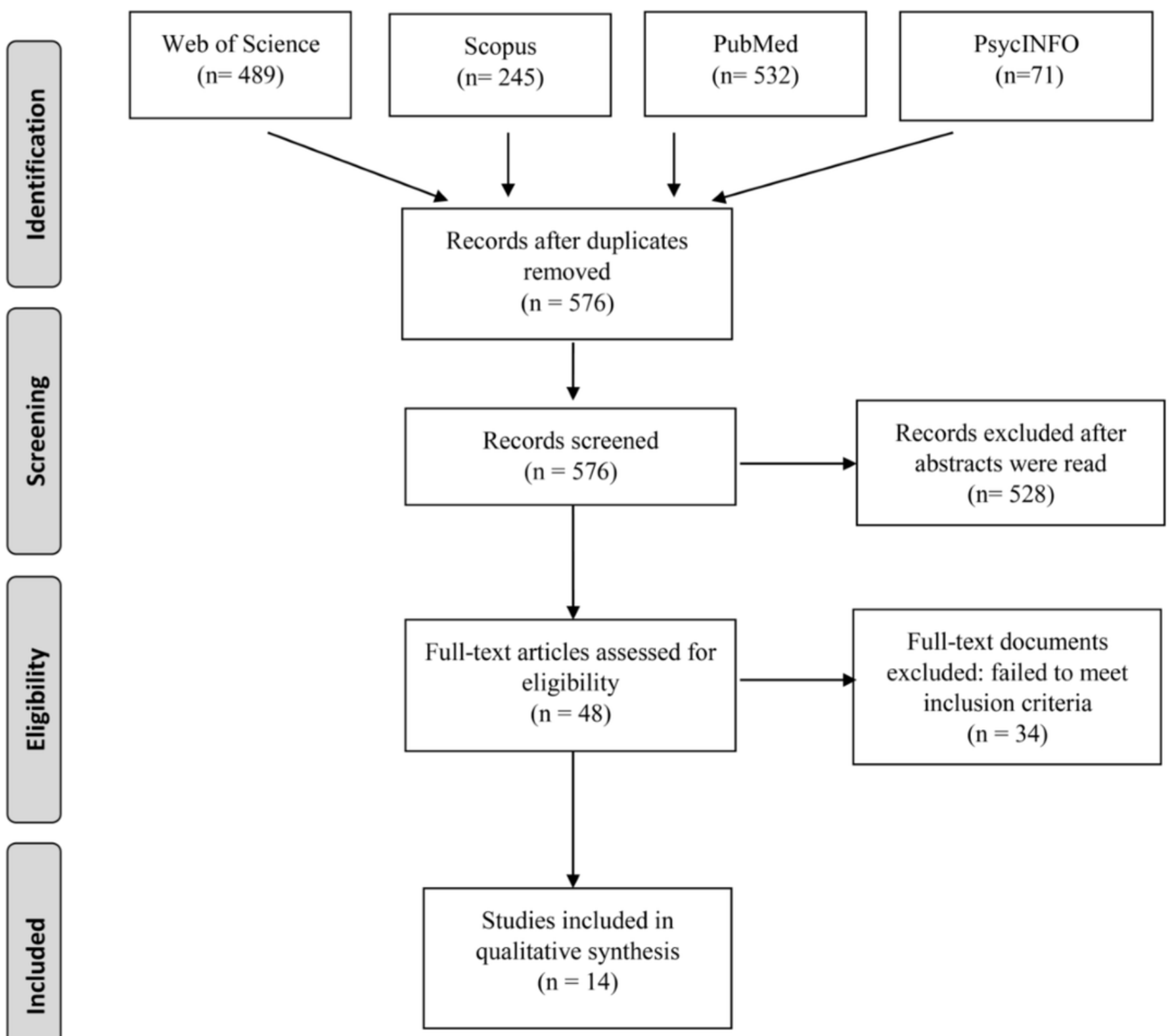


Figure 2

Google search trends for the term 'toilet paper' by different English-speaking countries.

(A) Australia. (B) USA. (C) Canada. (D) United Kingdom. (E) India. 
A.

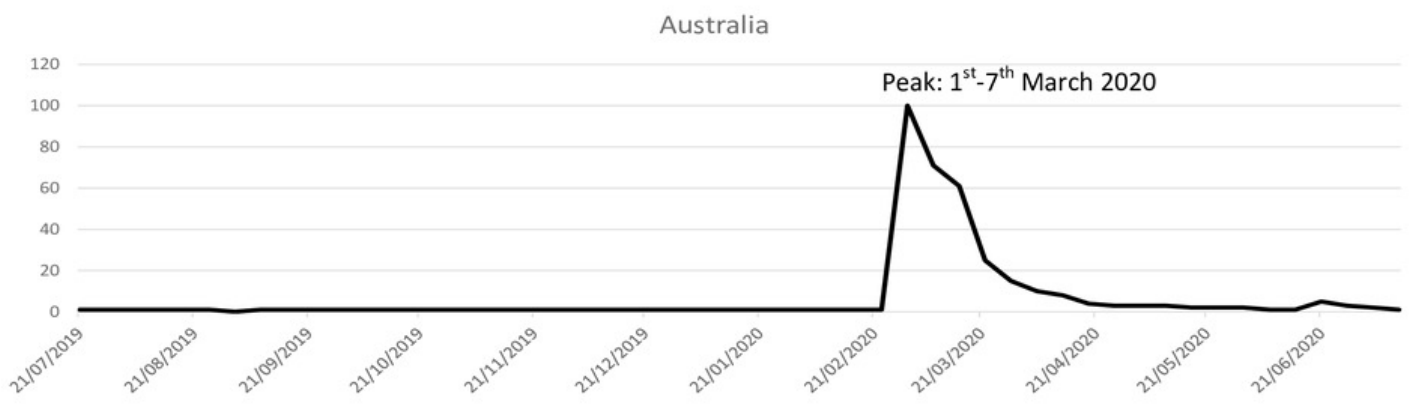

B.

USA

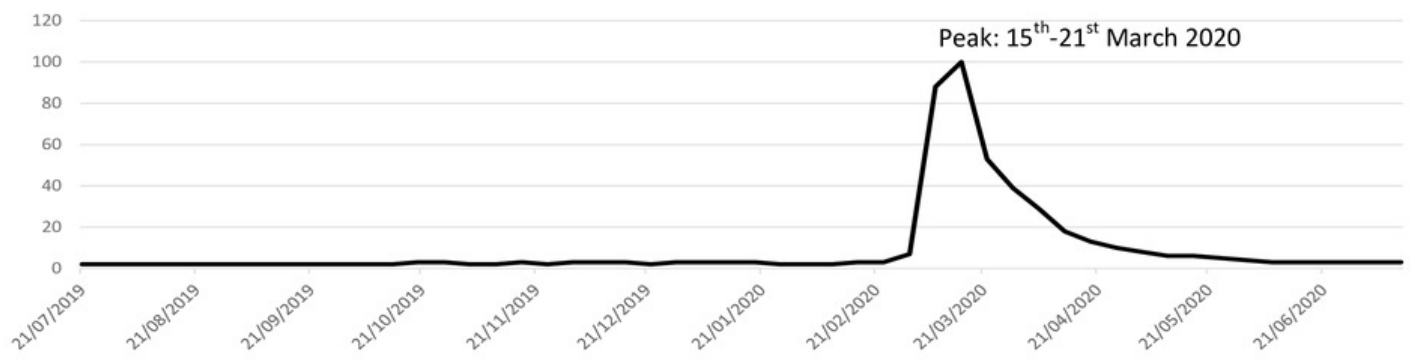

C.

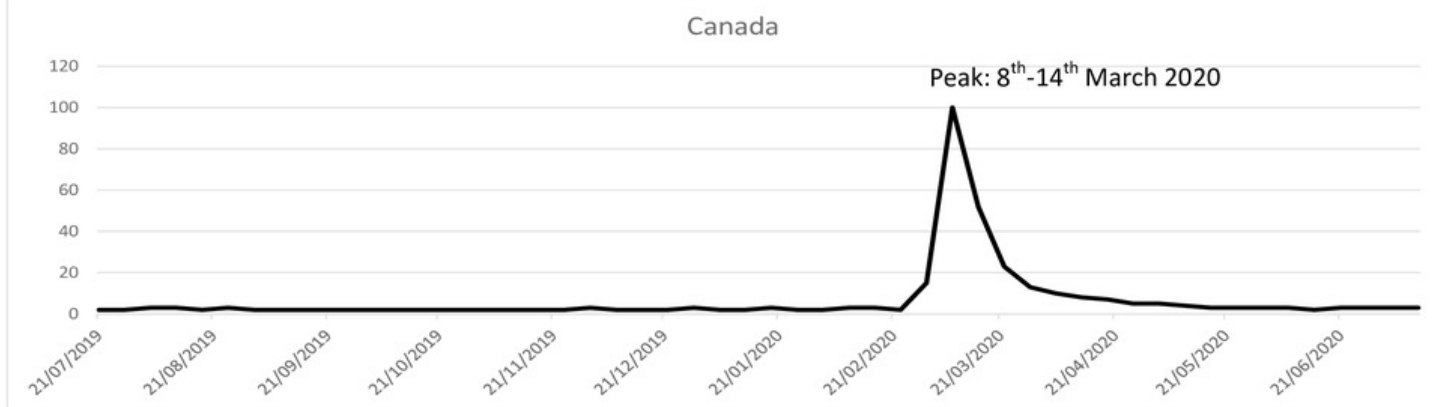

D.

United Kingdom

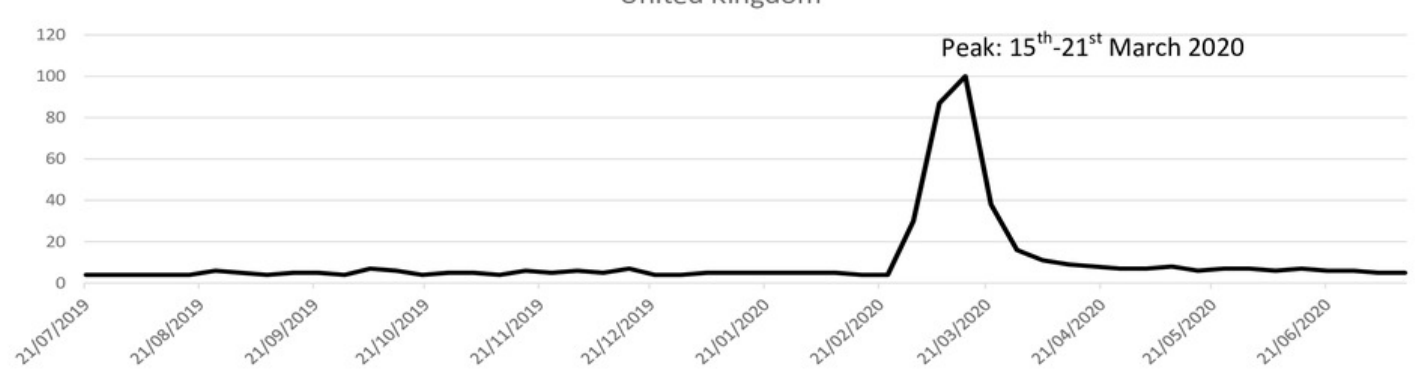

E. India

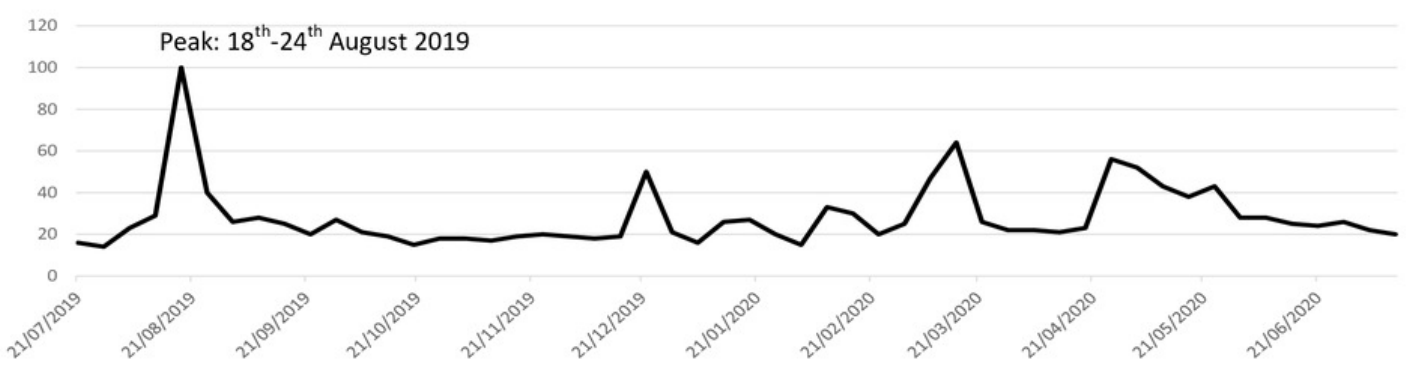




\section{Figure 3}

CATOTIM algorithm for managing paper toilet hoarding.

Abbreviations: CATOTIM= Catalan Toilet Tissue Research Group in Mental Health; PTSD= Post-traumatic stress disorder; $\mathrm{CT}=$ Computed tomography; $\mathrm{MRI}=$ Magnetic resonance imaging; $C S F=$ Cerebrospinal fluid; Shizoaffective $D .=$ Schizoaffective disorder; $O C D=$ Obsessive-compulsive disorder; DSM-5= Diagnostic and Statistical Manual of Mental Disorders $-5^{\text {th }}$ edition; $\mathrm{GAD}=$ Generalised anxiety disorder; $\mathrm{OCPD}=$ Obsessive-compulsive personality disorder.

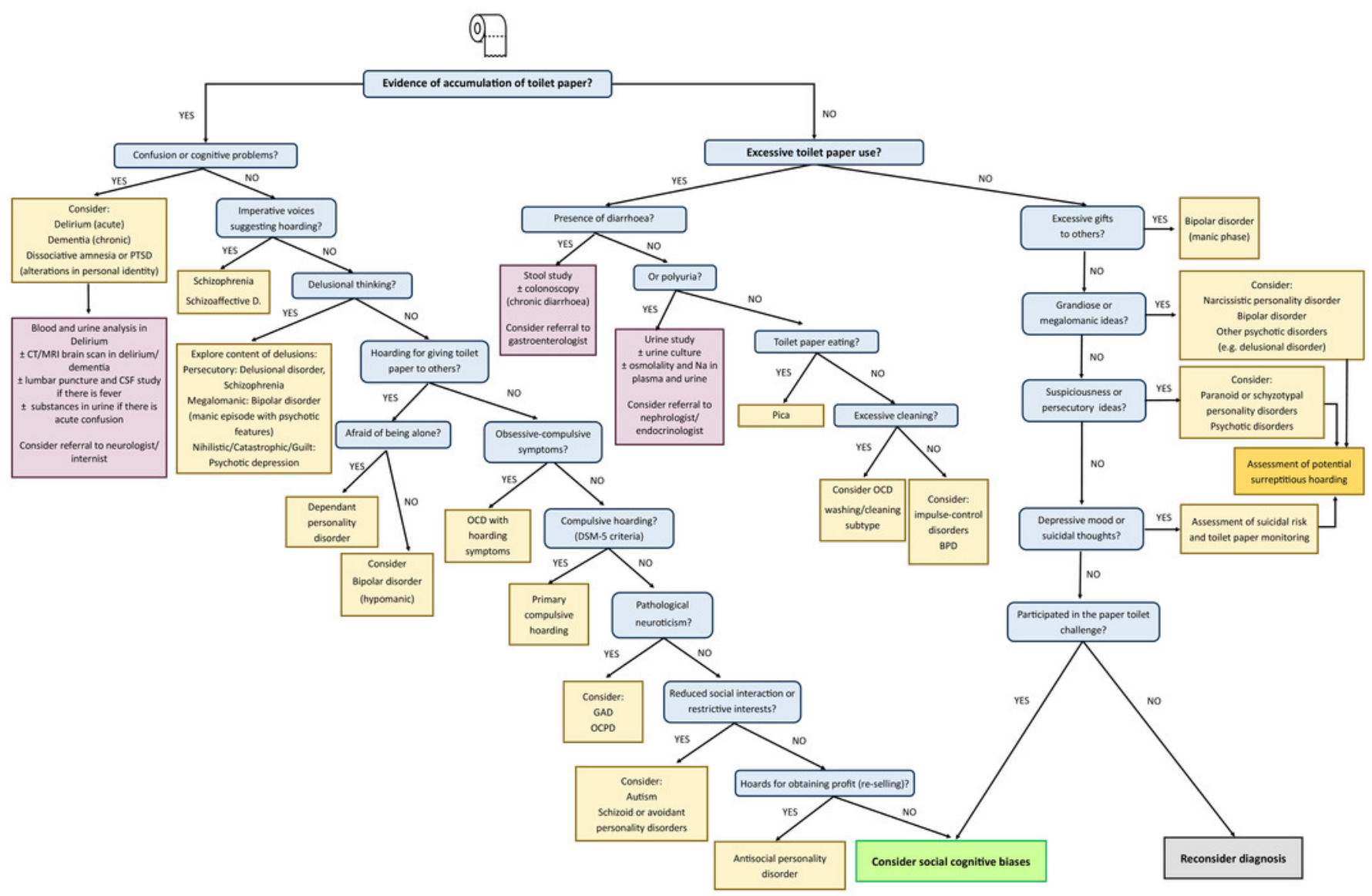

